\title{
Optical in vivo imaging detection of preclinical models of gut Optical in vivo imaging detection of preclinical models of gut tumors through the expression of integrin aV $\beta 3$
}

\author{
Giulia Marelli ${ }^{1,4}$, Roberta Avigni ${ }^{1}$, Paola Allavena ${ }^{1,2}$, Cecilia Garlanda ${ }^{1,2}$, Alberto \\ Mantovani ${ }^{1,2,3}$, Andrea Doni ${ }^{1}$ and Marco Erreni ${ }^{1}$ \\ ${ }^{1}$ IRCCS Humanitas Clinical and Research Center, Rozzano, Milan, Italy \\ ${ }^{2}$ Humanitas University, Rozzano, Milan, Italy \\ ${ }^{3}$ The William Harvey Research Institute, Queen Mary University of London, London, UK \\ ${ }^{4}$ Current address: Center for Molecular Oncology, Bart Cancer Institute, Queen Mary University of London, London, UK \\ Correspondence to: Marco Erreni, email: marco.erreni@humanitasresearch.it \\ Keywords: optical imaging; FMT; intestine tumor; integrin aVß3, colorectal cancer
}

Received: February 01, 2018

Accepted: July 12, 2018

Published: July 31, 2018

Copyright: Marelli et al. This is an open-access article distributed under the terms of the Creative Commons Attribution License 3.0 (CC BY 3.0), which permits unrestricted use, distribution, and reproduction in any medium, provided the original author and source are credited.

\section{ABSTRACT}

Optical imaging and Fluorescent Molecular Tomography (FMT) are becoming increasingly important for the study of different preclinical models of cancer, providing a non-invasive method for the evaluation of tumor progression in a relatively simple and fast way. Intestinal tumors, in particular colorectal cancer (CRC), represent a major cause of cancer-related death in Western countries: despite the presence of a number of preclinical models of intestinal carcinogenesis, there is a paucity of information about the possibility to detect intestinal tumors using fluorescent probes and optical in vivo imaging. Herein, we identify the detection of integrin av $\beta 3$ by FMT and optical imaging as an effective approach to assess the occurrence and progression of intestinal carcinogenesis in genetic and chemically-induced mouse models. For this purpose, a commercially available probe (IntegriSense), recognizing integrin av $\beta 3$, was injected in $\mathrm{APC}^{+/ \mathrm{min}}$ mice bearing small intestinal adenomas or CRC: FMT analysis allowed a specific tumor detection, further confirmed by subsequent ex vivo imaging or conventional histology. In addition, IntegriSense detection by FMT allowed the longitudinal monitoring of tumor growth. Taken together, our data indicate the possibility to use integrin av $\beta 3$ for the visualization of intestinal tumors in preclinical models.

\section{INTRODUCTION}

Colorectal cancer (CRC) is a frequent human neoplasia and still one of the major leading causes of cancer-related death, especially in Western Countries [1]. Both transplanted orthotopic and spontaneous mouse models of colorectal cancer are available, representing a fundamental tool to understand the biological mechanisms of tumor progression and to evaluate the efficacy of potential therapeutic approaches. However, to assess disease state without sacrificing the animals, only indirect parameters are commonly used, such as animal weight loss, food and water uptake, stool consistency or the presence of occult blood in the feces. On the other hand, invasive procedures such as conventional optical endoscopy can be operated, but with the risk of perforating the colon and bleeding, thus impacting on the quality of the analysis [2]. In addition, a 6-27\% miss rate recognition of small polyps have been estimated when samples are analysed by white light colonoscopy [3]. Different molecular in vivo imaging methods are now available, allowing the detection and the non-invasive characterization of tumor development in living animals, reducing the number of mice required per experiments and increasing the statistical power of the analysis. In preclinical oncological studies, in addition to conventional imaging techniques 
such as positron emission tomography (PET), magnetic resonance imaging (MRI), computed tomography (CT) and ultrasounds, optical imaging procedures can be used for the visualization of biological processes in small animal models expressing specific reporters (luciferase or fluorescent proteins) or injected with specific fluorescent probes [4-7]. However, a major drawback of conventional two-dimensional optical imaging is that the acquired signal is attenuated as much as the light source is deeper embedded in tissue. In this context, Fluorescent Molecular Tomography (FMT), a relatively new optical imaging technology, significantly improves the quality and the spatial resolution of optical imaging analysis, being able to localize and, more importantly, quantify fluorescent probes three-dimensionally in deep tissues at high sensitivity $[8,9]$.

The characterization of processes involved in neoplastic progression and the description of tumor features are of primary importance to determine the correct cancer staging and to identify the best prognostic, predictive or therapeutic approach for oncologic patients. In this scenario, the expression of integrins, has been demonstrated to influence the prognosis in various cancer types [10]. Integrins are small transmembrane heterodimeric glycoproteins involved in cell adhesion, cell-matrix interaction and cell signalling pathways, whose expression has been correlated with tumor cell migration and metastatic processes [11]. Among members of this family, integrin $\alpha v \beta 3$ is one of the most extensively studied and has been associated with the early phase of angiogenesis in a variety of tumors, including colorectal cancer $[12,13]$. In addition, studies demonstrated the efficacy of targeting integrin $\alpha v \beta 3$ for the imaging identification and therapeutic treatment of several tumors, such as breast cancer, lung cancer and glioblastomas [14, 15].

In this study, we provide evidence that imaging of integrin $\alpha v \beta 3$ can be successfully used for the visualization and detection of intestinal tumors in preclinical models. The methodology described here may represent an evaluable tool to analyse the pathogenesis of intestinal tumors and therapeutic drug development.

\section{RESULTS}

\section{In vivo detection by $\alpha \mathrm{v} \beta 3$ integrin expression of tumor formation in the small intestine}

To test the efficacy of targeting integrin $\alpha v \beta 3$ to visualize spontaneous genetic model of small intestine tumors, we took advantage of the $\mathrm{APC}^{+/ \mathrm{min}}$ (APC, Adenomatous Polyposis Coli) mouse model. $\mathrm{APC}^{+/ m i n}$ mice are characterized by a single point mutation in the murine homolog of the $A P C$ gene. These mice develop multiple adenomas in the small intestine, representing a very powerful and commonly used model to study intestinal carcinogenesis [16]. In addition, $\mathrm{APC}^{+/ \mathrm{min}}$ mice were previously crossed with mice lacking the expression of the chemokine receptor $\mathrm{CX}_{3} \mathrm{CR} 1$, known to have a role in regulating intestinal inflammation and whose absence induces intestinal carcinogenesis [17-20], in order to generate mice either competent $\left(\mathrm{APC}^{+/ \mathrm{min}_{-}} \mathrm{CX}_{3} \mathrm{CR}^{+/-}\right)$or

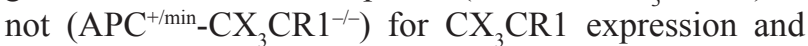
carrying concomitantly the mutation in $A P C$ gene. The double-mutant mice allowed us to compared not only tumor-bearing mice with healthy subjects, but also mice with a different tumor-load, due to the $\mathrm{CX}_{3} \mathrm{CR} 1$-dependent phenotype.

The occurrence of small intestine tumors was analysed by histology in 18 weeks-old $\mathrm{APC}^{+/ \mathrm{min}}$ mice and age-related WT mice (Figure 1A). Subsequently, we investigated the expression of integrin $\alpha v \beta 3$ in small intestine tumors. We excised tumor lesions or corresponding healthy mucosa from $\mathrm{APC}^{+/ m i n}$ and WT mice, respectively: mRNA analysis by q-PCR indicated that the levels of both $\alpha \mathrm{v}$ and $\beta 3$ subunits were significantly upregulated in small intestine tumors in comparison to corresponding healthy mucosa (Figure 1B).

To evaluate whether the expression of the integrin $\alpha v \beta 3$ could be used to detect small intestine tumor formation in vivo, $24 \mathrm{~h}$ before the imaging, 18 weeksold $\mathrm{APC}^{+/ m i n}$ mice and age-related WT mice were shaved and injected IV with $0.08 \mathrm{nmol} / \mathrm{g}$ of body weight of IntegriSense 750 (Perkin Elmer), a commercial available probe specifically recognizing integrin $\alpha v \beta 3$ [21] and emitting a near infrared (NIR) fluorescent signal at $750 \mathrm{~nm}$ wavelength. Animals have been fed with the AIN76A, alfalfa-free, rodent diet (Mucedola srl) for 2 weeks, in order to minimize the autofluorescence originating from the animals' intestinal contents. Mice were positioned in a dedicated imaging cassette and IntegriSense750 signal acquired with the fluorescent molecular tomography (FMT) imaging system FMT2000 (Perkin Elmer). A 3D ellipsoidal region of interest (ROI) was outlined to select, as much as possible, the small intestine. Subsequently, we quantified probe concentration (as $\mathrm{pmol} / \mathrm{mm}^{3}$ ) within the ROI: independently from the $\mathrm{CX}_{3} \mathrm{CR} 1$ status, IntegriSense accumulated in the small intestine and this accumulation strongly increased in small intestine of $\mathrm{APC}^{+/ m i n}$ mice compared to WT mice (Figure 2A and 2B).

To further confirm the specificity of the in vivo signal acquisition, both $\mathrm{APC}^{+/ \min }$ and WT mice were sacrificed and small intestine collected for ex vivo imaging analysis, performed with the IVIS Lumina III optical imaging system (Perkin Elmer). Ex vivo analysis confirmed the increased accumulation of IntegriSense 750 probe in the small intestine of tumor-bearing $\mathrm{APC}^{+/ m i n}$ mice compared to WT mice (Figure 2C and 2D): of note, several spots of probe accumulation can be identified in the small intestine of $\mathrm{APC}^{+/ m i n}$ mice (Figure $2 \mathrm{C}$, white arrows), likely corresponding to the localization of the developed multiple small adenomas. To further verify 
the accuracy and the correct positioning of the in vivo ROIs, we correlated the in vivo quantification of the IntegriSense750 probe and ex vivo acquired signal, finding a significant correlation between in vivo and ex vivo results $\left(r^{2} 0.72, p<0.0001\right)$, thus confirming the specificity of the detection (Figure 2E). In conclusion, $\mathrm{APC}^{+/ m i n}$ tumor-bearing mice show a higher accumulation of integriSense750 probe in comparison to WT mice, suggesting that more fluorescent signal corresponds to an increased tumor load in $\mathrm{APC}^{+/ m i n}$ mice.

Finally, given the role of $\mathrm{CX}_{3} \mathrm{CR} 1$ in regulating intestinal inflammation, we compared the formation of small intestine adenomas in $\mathrm{APC}^{+/ m i n}-\mathrm{CX}_{3} \mathrm{CR}^{+/}$and $\mathrm{APC}^{+/}$ ${ }^{m i n}{ }_{-} \mathrm{CX}_{3} \mathrm{CR}^{-/}{ }^{-}$. When the $\mathrm{CX}_{3} \mathrm{CR} 1$ status was considered,

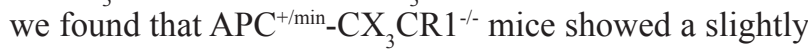
but significant increased accumulation of IntegriSense 750 probe compared to $\mathrm{APC}^{+/ m i n}{ }_{-} \mathrm{CX}_{3} \mathrm{CR}^{+/-}$mice both in in vivo $\mathrm{FMT}$ and ex vivo imaging analysis (Figure $3 \mathrm{~A}, 3 \mathrm{~B}$ and Figure 3C, 3D, respectively), confirming our (and other) previous results of increased tumor occurrence in $\mathrm{CX}_{3}$ CR1-deficient mice $[20,22]$. This result indicates that IntegriSense 750 is able not only to distinguish tumor tissue from healthy mucosa, but also to discriminate between different tumor load in small intestine adenomasbearing mice.

\section{In vivo detection of tumor formation in the colon by $\alpha v \beta 3$ integrin expression}

We subsequently evaluated the feasibility of targeting integrin $\alpha v \beta 3$ in a chemically-induced mouse model of colon cancer. $\mathrm{APC}^{+/ m i n}$ mice spontaneously

\section{A}
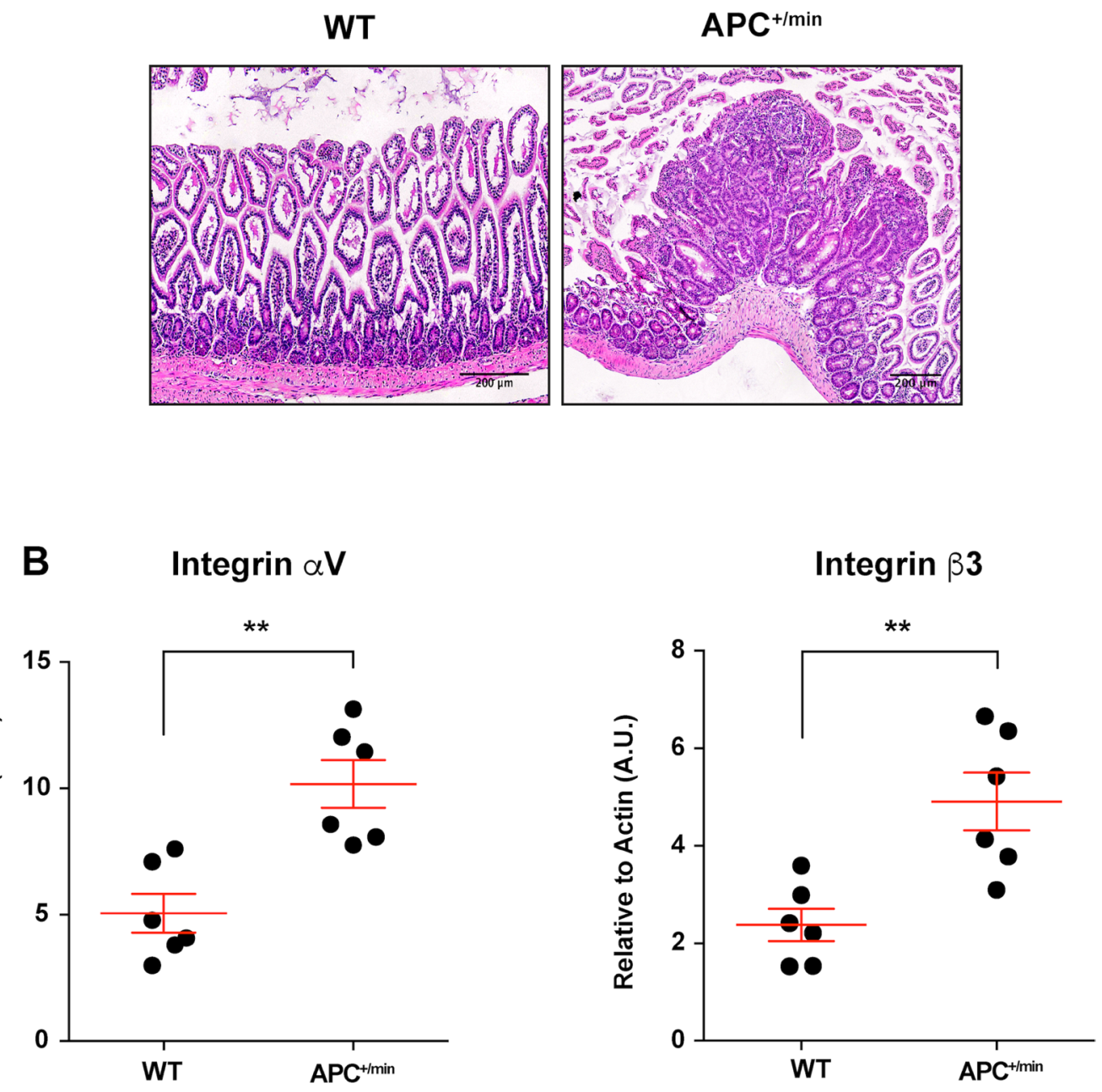

Figure 1: Integrin $\alpha \mathrm{V} \beta 3$ expression in small intestine of 18 weeks old $\mathrm{APC}^{+/ \mathrm{min}}$ and WT mice. (A) Histological analysis of small intestine tumor occurrence in 18 weeks old $\mathrm{APC}^{+/ \min }$ mice and age-related WT mice. Original magnification $10 \times$. (B) Evaluation of mRNA expression of $\alpha \mathrm{V}$ and $\beta 3$ integrin subunit by qPCR in healthy (WT) and tumor tissue (APC ${ }^{+/ m i n}$ ). Data are presented as Mean \pm SEM. Student's $t$ Test, ${ }^{* *} p<0.01$. 
develop multiple adenomas in the small intestine but few in the colon. To induce the formation of colorectal tumors, $\mathrm{APC}^{+/ m i n}$ and WT mice were administered with dextran sulfate sodium (DSS) in drinking water: DSS is a widely used irritant of the colonic mucosa, able to cause intestinal
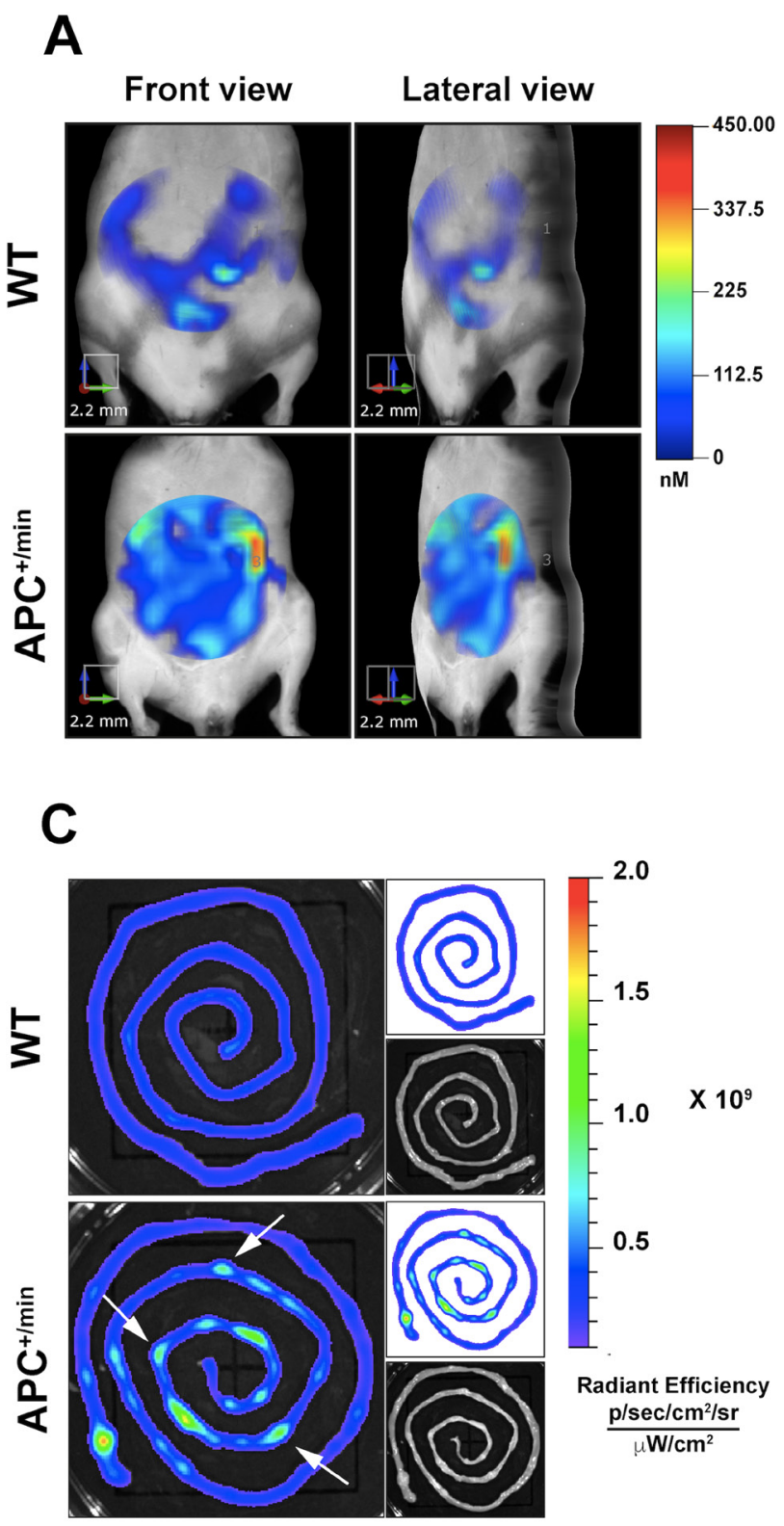

inflammation (in a B- and T-cell independent manner), likely through the damaging of epithelial monolayer lining the large intestine and the consequent dissemination of pro-inflammatory luminal content into the tissue [23]. We administered 3\% DSS to 4 weeks-old $\mathrm{APC}^{+/ \min }$ and

\section{B}
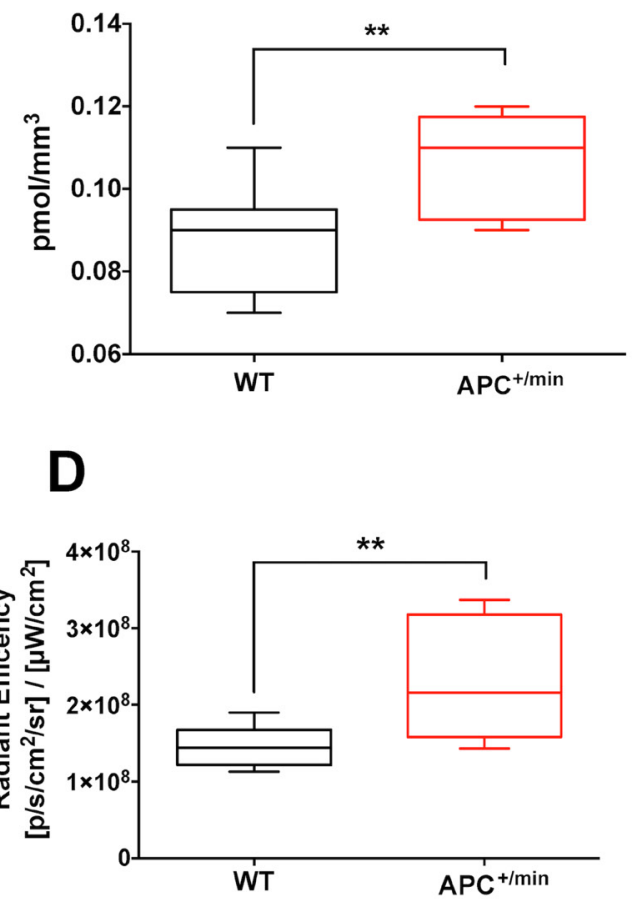

E

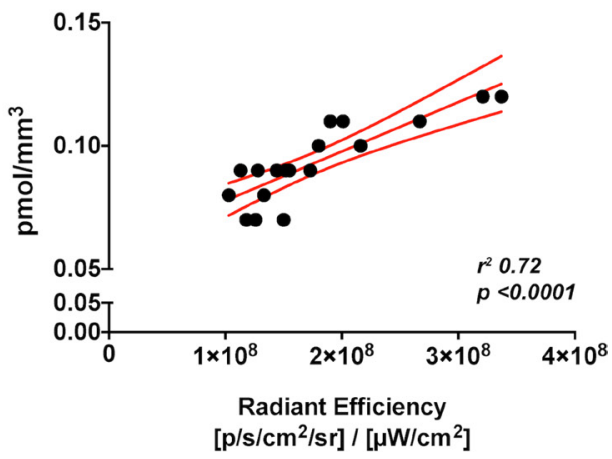

Figure 2: In vivo and ex vivo imaging detection of small intestine tumor by IntegriSense750 probe. (A) In vivo Fluorescent Molecular Tomography (FMT) analysis of IntegriSense750 accumulation in the small intestine of 18 weeks old APC ${ }^{+/ m i n}$ and WT mice. Region of interest (ROI) was tri-dimensionally defined to outline the small intestine. The colorbar shows the concentration (in $\mathrm{nM}$ ) of the IntegriSense 750 probe. (B) Quantification of FMT analysis of IntegriSense 750 probe accumulation in the small intestine of 18 weeks old $\mathrm{APC}^{+/ \mathrm{min}}$ and WT mice. The total amount of probe within the ROI (in pmoles) was calculated as indicated in the M\&M. The amount of pmoles of the probe was normalized based on the volume $\left(\mathrm{mm}^{3}\right)$ of the ROI, after adjustment using the statistically derived threshold value. Data are presented as min and max whiskers plot. Student's $t$ Test, ${ }^{* *} p<0.01$. (C) Ex vivo analysis of the small intestine of APC ${ }^{+/ m i n}$ and WT mice previously acquired by FMT. The colorbar shows the Radiant Efficiency. White arrows indicate the accumulation of IntegriSense 750 probe in the neoplastic lesions. (D) Quantification of the ex vivo analysis of IntegriSense 750 probe accumulation in the small intestine of $\mathrm{APC}^{+/ \min }$ and WT mice. Data are presented as min and max whiskers plot. Student's $t$ Test, ${ }^{* *} p<0.01$ (E) Correlation between in vivo FMT quantification $\left(\mathrm{pmol} / \mathrm{mm}^{3}\right)$ and ex vivo quantification (Radiant Efficiency) of IntegriSense 750 accumulation in the small intestine of both $\mathrm{APC}^{+/ \mathrm{min}}$ and WT mice. Data are presented as Mean and Error $(95 \% \mathrm{CI})$. Linear regression was calculated $\left(r^{2} 0.72, p<0.0001\right)$. 
WT mice for 7 days, followed by 4 weeks of fresh water $[20,24]$. The occurrence of tumors was assessed by histology, comparing colon from $\mathrm{APC}^{+/ \mathrm{min}}$ and WT DSStreated mice (Figure 4A). Subsequently, we evaluated the mRNA expression of integrin $\alpha v \beta 3$. We excised tumor lesions or corresponding healthy mucosa from the colon of DSS-treated $\mathrm{APC}^{+/ \text {min }}$ and DSS-treated WT mice, respectively: mRNA analysis by qPCR indicated a significant increase in the expression of the $\beta 3$ subunit in tumor lesions of DSS-treated APC ${ }^{+/ m i n}$ mice (Figure 4B).

We then evaluated in vivo the expression of integrin $\alpha v \beta 3.24 \mathrm{~h}$ before the acquisition, mice were shaved and injected IV with $0.08 \mathrm{nmol} / \mathrm{g}$ of body weight of IntegrinSense750. Also in this case, animals have been

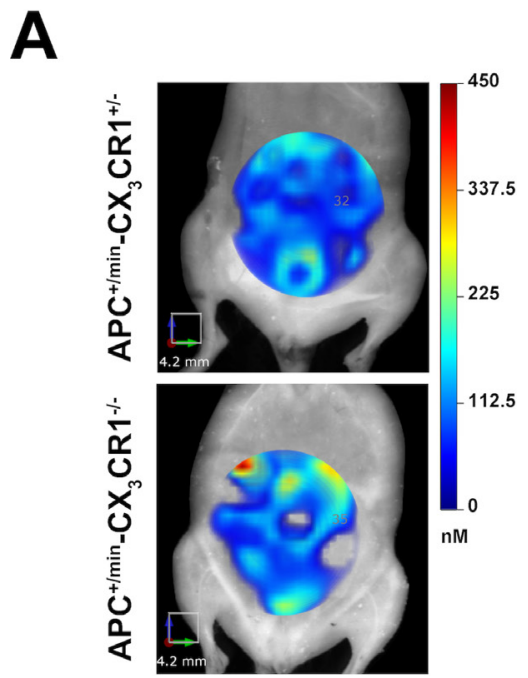

B
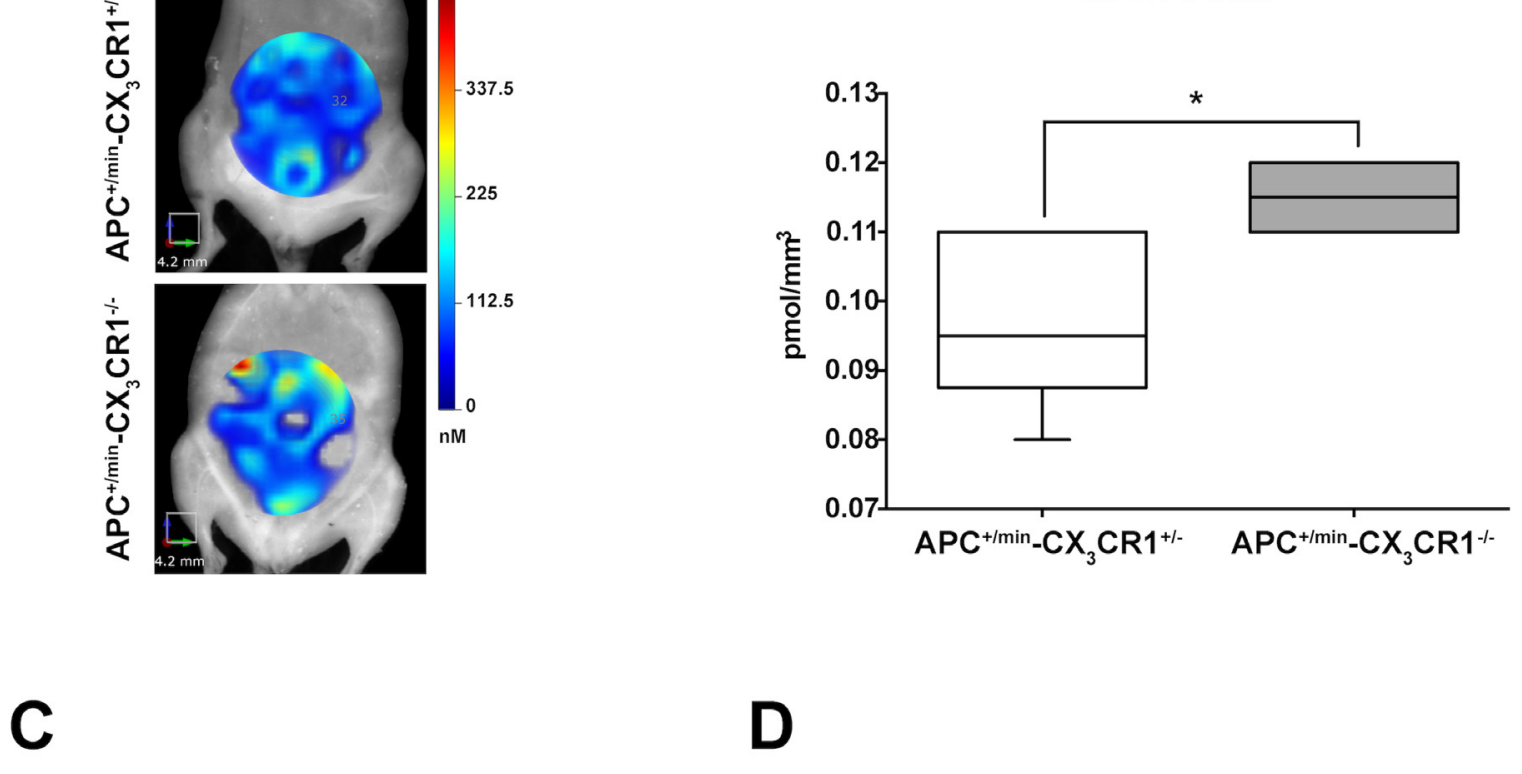

D

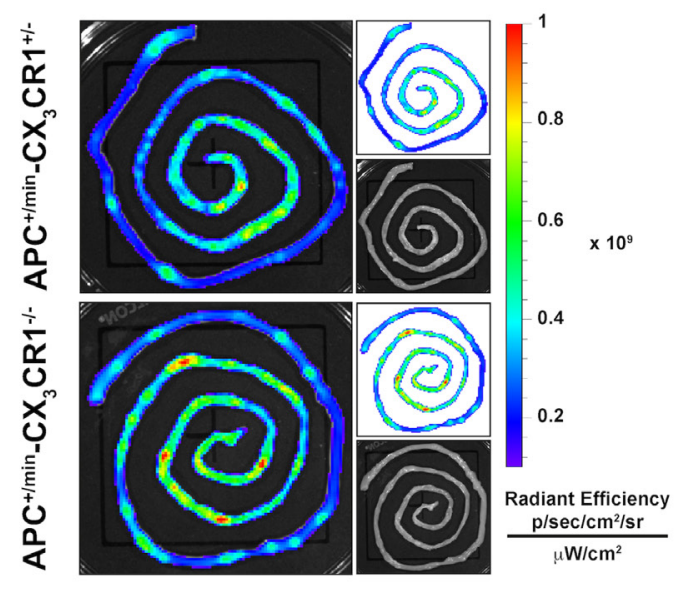

Ex vivo 2D imaging

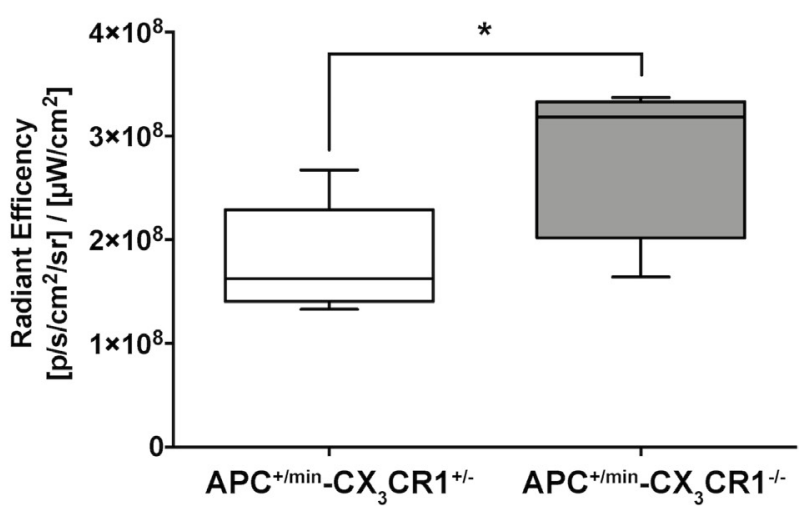

Figure 3: In vivo and ex vivo imaging analysis of IntegriSense 750 accumulation in the small intestine of $\mathrm{APC}^{+/ m i n}$ -

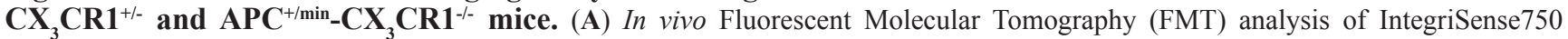
accumulation in the small intestine of 18 weeks old $\mathrm{APC}^{+/ m_{i n}}-\mathrm{CX}_{3} \mathrm{CR}^{+/-}$and $\mathrm{APC}^{+/ m i n}-\mathrm{CX}_{3} \mathrm{CR}^{-/}$mice. Region of interest (ROI) was tridimensionally defined to outline the small intestine. The colorbar shows the concentration (in nM) of the IntegriSense750 probe. (B) FMT

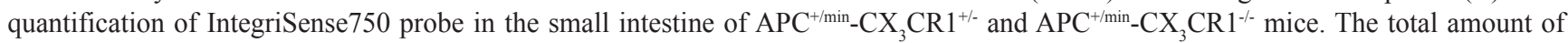
probe within the ROI (in pmoles) was calculated relative to the internal standard generated with a known concentration of the appropriate NIR dye, following manufacturer's instruction. The amount of pmoles of the probe was normalized based on the volume ( $\left.\mathrm{mm}^{3}\right)$ of the ROI, after adjustment using the statistically derived threshold value. Data are presented as min and max whiskers plot. Student's $t$ Test, ${ }^{*} p<0.05$

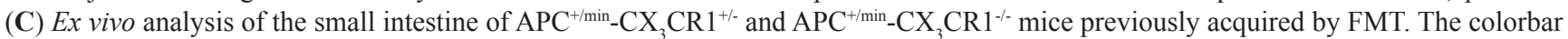
shows the Radiant Efficiency. (D) Ex vivo quantification of the IntegriSense 750 probe in the small intestine of $\mathrm{APC}^{+/ \mathrm{min}_{-} \mathrm{CX}} \mathrm{CR}_{3}^{+/-}$and $\mathrm{APC}^{+/ \min }-\mathrm{CX}_{3} \mathrm{CR}^{-/-}$mice. Data are presented as min and max whiskers plot. Student's $t$ Test, ${ }^{*} p<0.05$. 
fed for 2 weeks with AIN76A, alfalfa-free, rodent diet. Mice were positioned in the dedicated imaging cassette and IntegriSense750 signal acquired with FMT2000 system. A cylindrical 3D region of interest (ROI) was outlined in order to select, as much as possible, the colon. Independently from the $\mathrm{CX}_{3} \mathrm{CR} 1$ status, probe quantification revealed higher accumulation of the IntegriSense 750 in the colon of DSS-treated $\mathrm{APC}^{+/ \text {min }}$ mice compared to DSS-treated WT mice (Figure 5A and 5B).

Subsequently, both $\mathrm{APC}^{+/ \mathrm{min}}$ and WT DSS-treated mice were sacrificed and colon collected for ex vivo imaging analysis by IVIS system, clearly confirming the increased concentration of IntegriSense 750 probe in the colon of $\mathrm{APC}^{+/ m i n}$ mice compared to WT mice (Figure 5C and 5D): in particular, IntegriSense750 accumulation specifically corresponds to the visible colonic neoplastic lesions of $\mathrm{APC}^{+/ m i n}$ DSS-treated mice (Figure 5C). Also in this case, even if the $r^{2}$ is poor, a significant linear correlation was found between the in vivo FMT concentration of the IntegriSense 750 probe and ex vivo IVIS acquired signal, confirming the specificity of the detection $\left(r^{2} 0.21\right.$, $p<0.02$, Figure 5E).

Finally, we compared the formation of colorectal tumors in $\mathrm{APC}^{+/ \mathrm{min}}-\mathrm{CX}_{3} \mathrm{CR}^{+/}$and

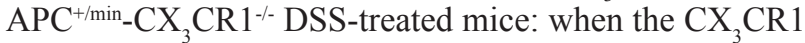
status was considered, we did not find any difference in the IntegriSense750 accumulation between $\mathrm{APC}^{+/ \mathrm{min}_{-}}$ $\mathrm{CX}_{3} \mathrm{CR}^{+/-}$and $\mathrm{APC}^{+/ \text {min}_{-}} \mathrm{CX}_{3} \mathrm{CR}^{-/-}$mice (data not shown).

A
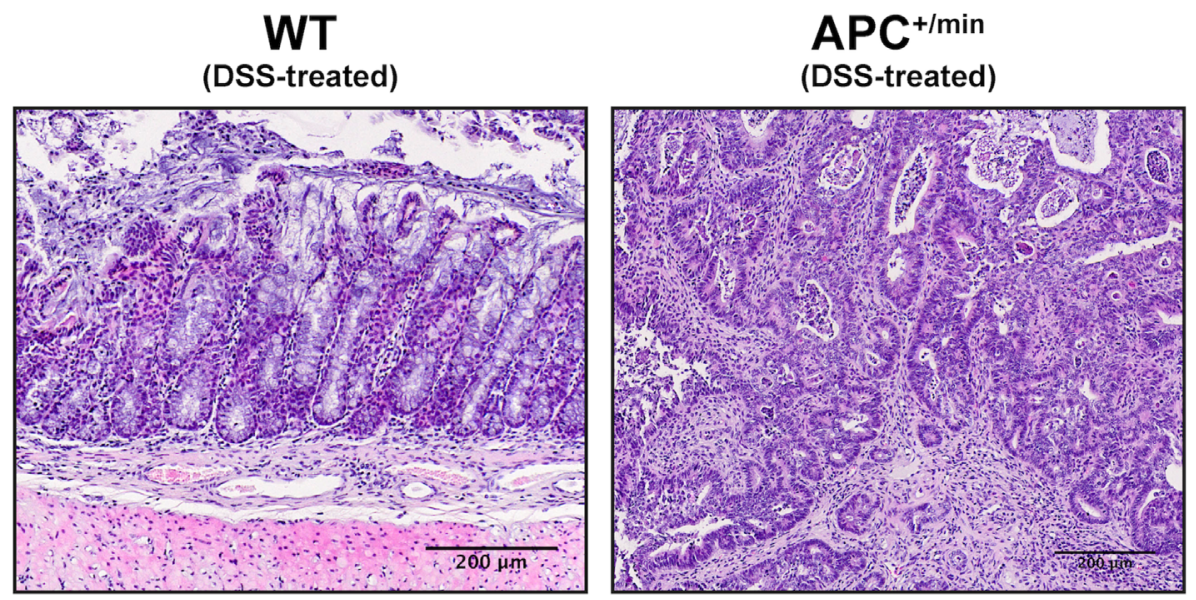

B

Integrin $\alpha \mathbf{V}$

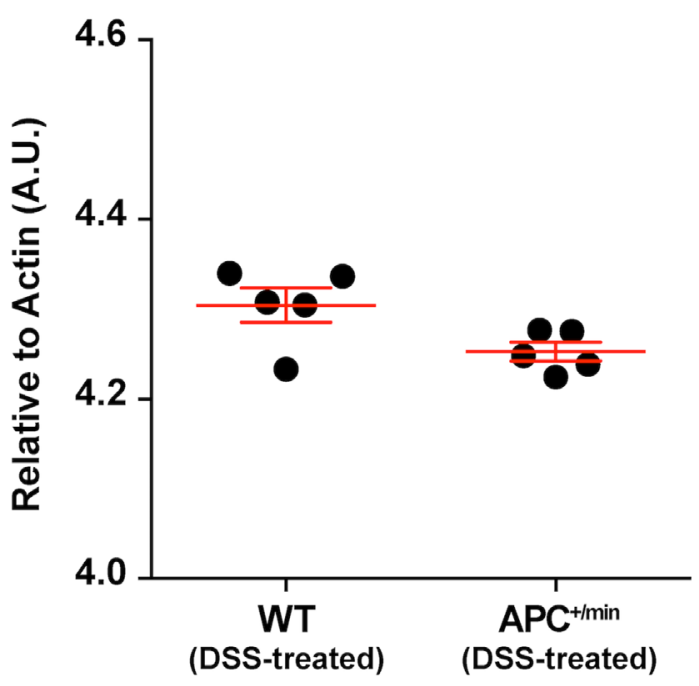

\section{Integrin $\beta 3$}

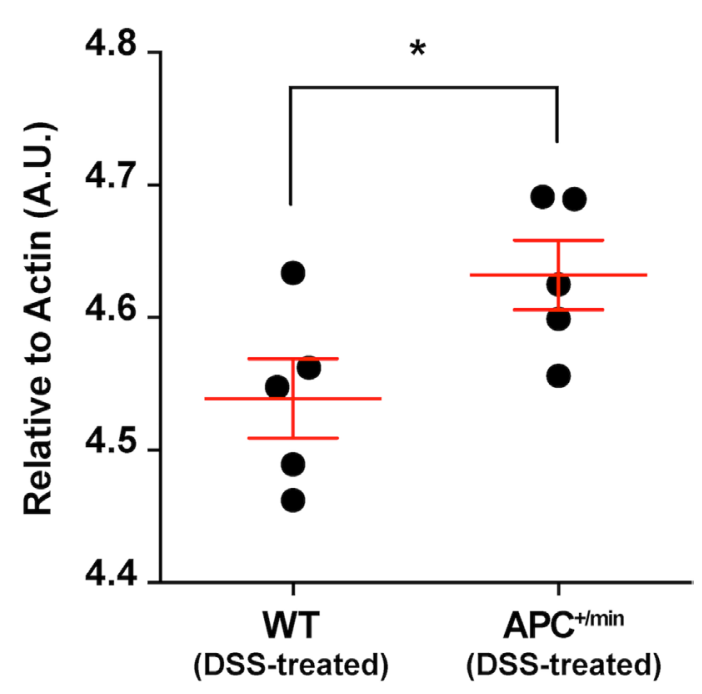

Figure 4: Integrin $\alpha \mathrm{V} \beta 3$ expression in the colon of DSS-treated $\mathrm{APC}^{+/ \mathrm{min}}$ and DSS-treated WT mice. (A) Histological analysis of colorectal tumor occurrence in $\mathrm{APC}^{+/ \min }$ mice and age-related WT mice after dextran sulfate sodium (DSS) administration (as described in the "Results" section). Original magnification $10 \times(\mathbf{B})$ Evaluation of mRNA expression of $\alpha \mathrm{V}$ and $\beta 3$ integrin subunit by qPCR in healthy (WT) and tumor $\left(\mathrm{APC}^{+/ \mathrm{min}}\right)$ tissue. Data are presented as Mean \pm SEM. Student's $t$ Test, ${ }^{*} p<0.05$. 


\section{Correlation between in vivo and ex vivo av $\beta 3$ integrin detection and histological analysis}

Histology still represents the leading technique for the evaluation of tumor occurrence and dimension. We therefore compared the results obtained from the in vivo and ex vivo imaging acquisition with the histological analysis. Small intestine tumor and colon cancer from mice previously analysed for the expression of IntegriSense 750 probe were collected and stained with hematoxylin and eosin. Sections were scanned with VS120-S5 Virtual Slide System (Olympus).

\section{A}

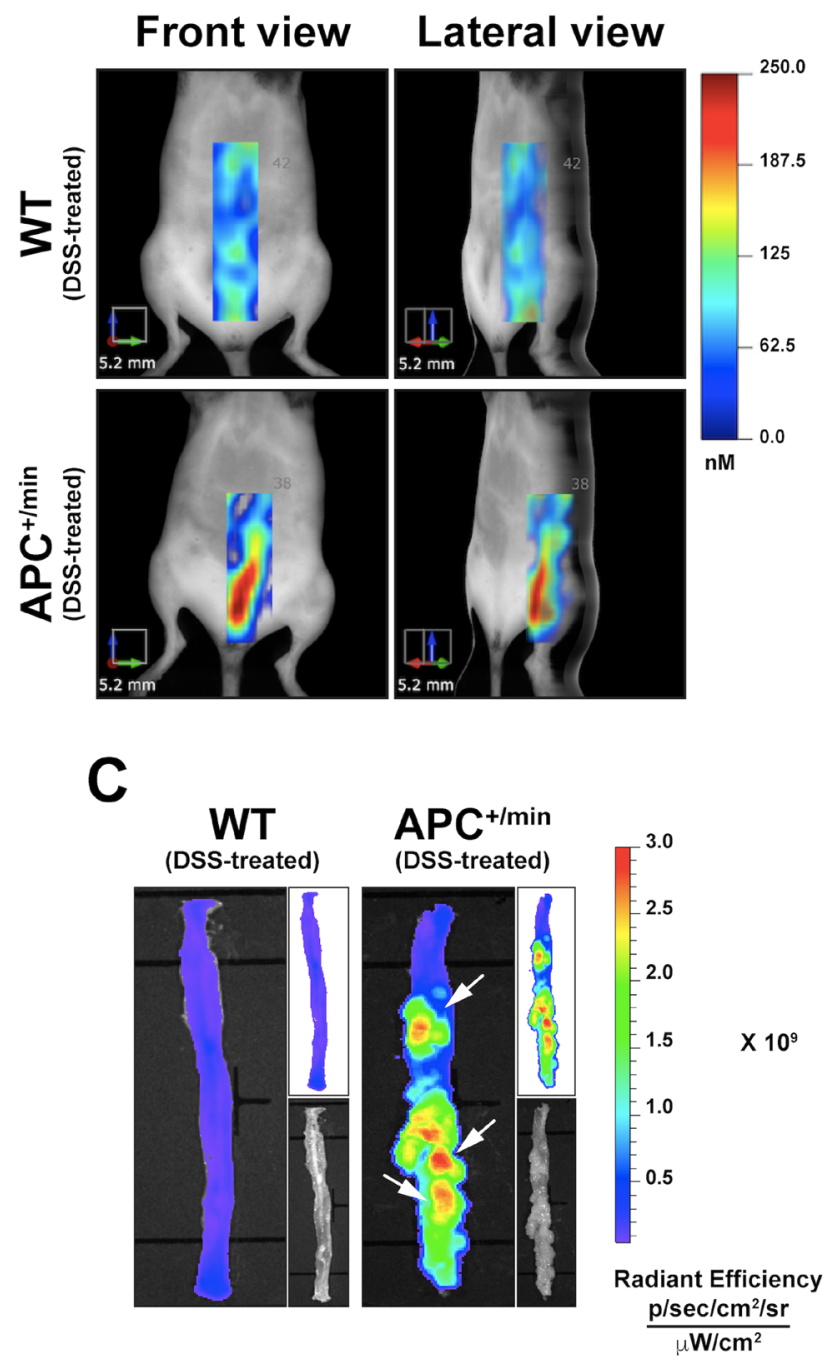

B
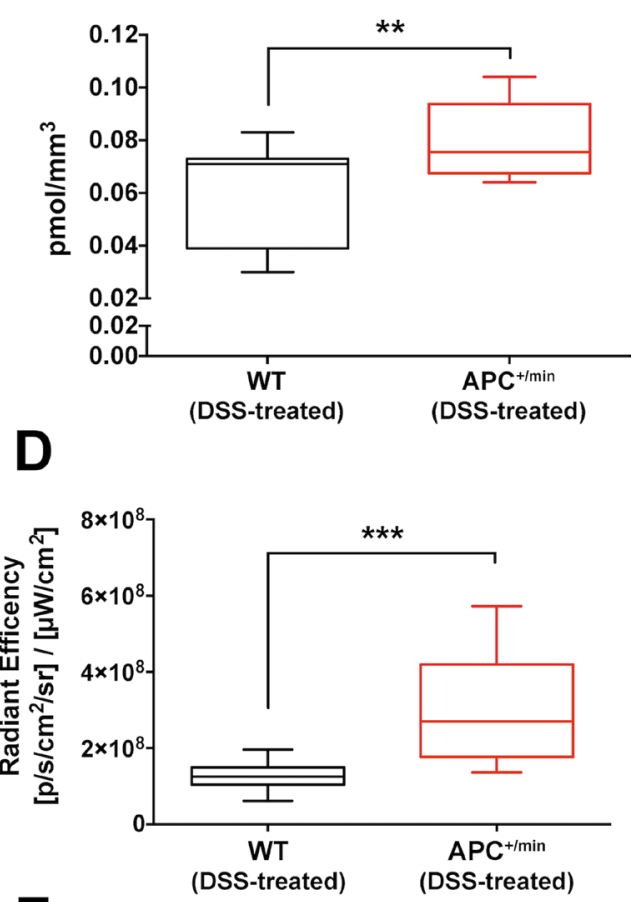

E

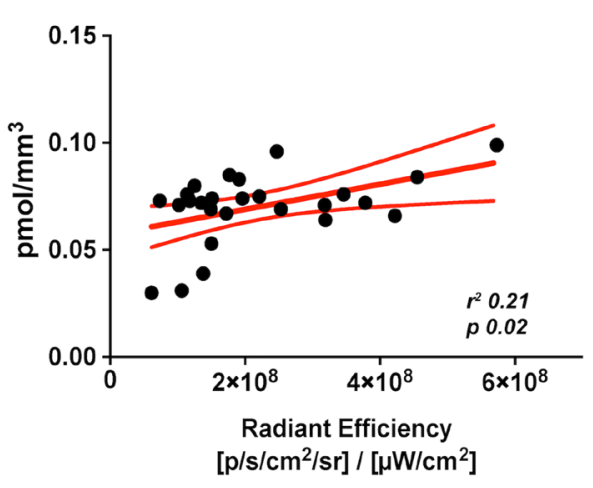

Figure 5: In vivo and ex vivo imaging detection of colorectal tumor by IntegriSense750 probe. (A) In vivo Fluorescent Molecular Tomography (FMT) analysis of IntegriSense750 accumulation in the colon of the DSS-treated APC ${ }^{+/ \min }$ and DSS-treated WT mice. Region of interest (ROI) was tri-dimensionally defined to outline the colon. The colorbar shows the concentration (in $\mathrm{nM}$ ) of the IntegriSense750 probe. (B) Quantification of FMT analysis of IntegriSense750 probe accumulation in the colon of DSS-treated APC ${ }^{+/ m i n}$ and DSS-treated WT mice. The total amount of probe within the ROI (in pmoles) was calculated as indicated in M\&M. The amount of pmoles of the probe was normalized based on the volume $\left(\mathrm{mm}^{3}\right)$ of the ROI, after adjustment using the statistically derived threshold value. Data are presented as min and max whiskers plot. Student's $t$ Test, ${ }^{* *} p<0.01$ (C) Ex vivo analysis of the colon of DSS-treated APC ${ }^{+/ m i n}$ and DSS-treated WT mice previously acquired by FMT. The colorbar shows the Radiant Efficiency. White arrows indicate the accumulation of IntegriSense750 probe in the tumor lesions. (D) Quantification of the ex vivo analysis of IntegriSense750 probe accumulation in the colon of DSS-treated APC ${ }^{+/ \min }$ and DSS-treated WT mice. Data are presented as min and max whiskers plot. Student's $t$ Test, ${ }^{* * *} p<0.001$ (E) Correlation between in vivo FMT quantification $\left(\mathrm{pmol} / \mathrm{mm}^{3}\right.$ ) and ex vivo quantification (Radiant Efficiency) of IntegriSense 750 accumulation in the colon of DSS-treated APC ${ }^{+/ m i n}$ and DSS-treated WT mice. Data are presented as Mean and Error $(95 \%$ CI). Linear regression was calculated $\left(r^{2} 0.21, p=0.02\right)$. 
Subsequently, we calculated the percentage of tumor area as described in "Material and Methods". We then correlated the results obtained from the in vivo and ex vivo imaging analysis with the percentage of tumor area. Interestingly, we found a significant correlation between the small intestine tumor area and the quantification of IntegriSense750 acquired both in vivo with FMT $\left(r^{2} 0.79\right.$, p 0.02, Figure 6A) and ex vivo with the IVIS system $\left(r^{2} 0.68, p 0.04\right.$, Figure 6B). In particular, some spots of IntegriSense 750 accumulation distinguished with the $e x$ vivo analysis corresponded to small adenomas identified by conventional histological analysis (Figure 6C, whitedotted line squares, and Figure 6D).

The same correlation was performed on colon tumors. In this case, a significant correlation was found only between histological analysis and the ex vivo acquisition with IVIS system $\left(r^{2} 0.44, p 0.03\right.$, Figure $\left.6 \mathrm{~F}\right)$, even if a tendency was observed also for the FMT analysis $\left(r^{2} 0.08, p 0.39\right.$, Figure 6E). As for the small intestine tumors, the spots of IntegriSense750 accumulation detected by ex vivo imaging analysis matched with colonic tumors recognizable by conventional histological analysis (Figure 6G, white-dotted line squares, and Figure 6H).

\section{Expression of IntegriSense probe within tumor tissue}

Integrin $\alpha v \beta 3$ is probably the integrin most strongly involved in the regulation of angiogenesis. Moreover, it is extensively reported that it binds to a wide range of extracellular matrix (ECM) proteins. To investigate the expression pattern of IntegriSense probe, mice bearing tumors in the small intestine or in the colon were IV injected with $0.08 \mathrm{nmol} / \mathrm{g}$ of body weight of IntegriSense680 (Perkin Elmer), a probe analogous to the IntegriSense750 previously used but emitting a fluorescent signal at $680 \mathrm{~nm}$ wavelength. After $24 \mathrm{~h}$, mice were sacrificed and small intestine and colon collected. Ex vivo IVIS imaging confirmed that the expression pattern of IntegriSense680 was comparable to the one previously observed with IntegriSense 750 (Supplementary Figure 1A and 1B). Subsequently, tissues were analysed by immunofluorescence: confocal microscopy analysis confirmed the upregulation of IntegriSense probe in neoplastic tissues $\left(\mathrm{APC}^{+/ \mathrm{min}}\right)$ compared to healthy mucosa (WT), both in small intestine and colon tumors (Figure $7 \mathrm{~A}$ and $7 \mathrm{~B}$, respectively). Of note, the localization of the probe was similar between small intestine tumor and colon tumors.

To confirm the colocalization of IntegriSense probe with ECM proteins, tissues were analysed for the expression of $\alpha$-smooth muscle actin ( $\alpha$-SMA) and fibrin: as expected, we observed several spots of colocalization between IntegriSense and both $\alpha$-SMA and fibrin in small intestine and colon tumors (Figure 7C and 7D, respectively).
As extensively reported in the literature, integrin $\alpha v \beta 3$ is strongly involved in the regulation of angiogenesis. We therefore stained tissues with an anti-CD31 antibody to specifically identify vessels: white arrows in Figure $7 \mathrm{C}$ and $7 \mathrm{D}$ indicate the colocalization between IntegriSense and $\mathrm{CD} 31^{+}$vessels, confirming the expression of integrin $\alpha v \beta 3$ by tumor-associated vessels in both small intestine and colon tumor (Figure 7C and 7D, respectively).

\section{In vivo monitoring of small intestine and colon cancers}

The main advantage of the non-invasive in vivo imaging technique is the possibility to monitor deep tumor growth without the need to sacrifice mice. We therefore investigated if the expression of integrin $\alpha v \beta 3$ could be used as a marker to follow both small intestine tumor and colon cancer progression.

For the small intestine tumor model, independently from the $\mathrm{CX}_{3} \mathrm{CR} 1$ status, $\mathrm{APC}^{+/ m i n}$ and WT mice were shaved and injected, $24 \mathrm{~h}$ before the acquisition, with $0.08 \mathrm{nmol} / \mathrm{g}$ of body weight of IntegriSense 750 probe after 14 and 18 weeks of age. As shown in Figure 8A and 8B, a significant increased accumulation of IntegriSense 750 was already detectable in 14 weeks-old $\mathrm{APC}^{+/ m i n}$ mice compared to age-matched WT mice; in addition, we observed a close to significant $(p=0.28)$ signal increase from 14 to 18 weeks, a result presumably compatible with a progression of the disease, while no difference was found over time in WT mice (Figure 8A and 8B).

In the colon cancer model, a close to significant higher IntegriSense750 accumulation was already detectable 2 weeks after the end of the DSS administration (Figure $8 \mathrm{C}$ and $8 \mathrm{D}, p=0.06$ ). Interestingly, IntegriSense 750 accumulation increased between the second and the fourth week after DSS administration in $\mathrm{APC}^{+/ m i n}$ tumor-bearing mice, while no differences were observed in WT mice. Of note, at this latter time point (4 weeks), IntegriSense750 accumulation is significantly higher in DSS-treated $\mathrm{APC}^{+/ m i n}$ tumor-bearing mice compared to DSS-treated WT mice (Figure 8C and 8D). These results indicate that IntegriSense 750 probe can be used to monitor tumor growth in both small and large intestine tumor progression.

\section{DISCUSSION}

The identification of new tumor biomarkers increases the opportunity of an early detection and the possibility of a more effective therapeutic intervention [25]. In this study, we demonstrated that integrin $\alpha v \beta 3$ is overexpressed in intestinal lesions compared to corresponding healthy mucosa and its visualization by Fluorescent Molecular Tomography (FMT) can be used for the early in vivo detection of both small and large intestine tumors. We found that the commercially available 
A

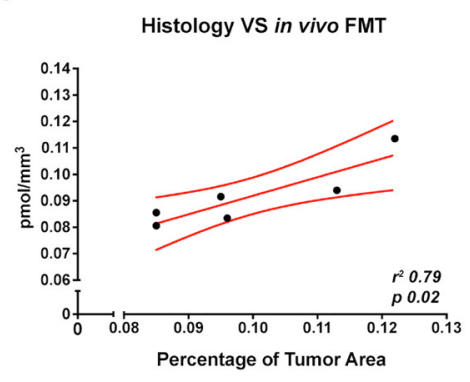

B

C
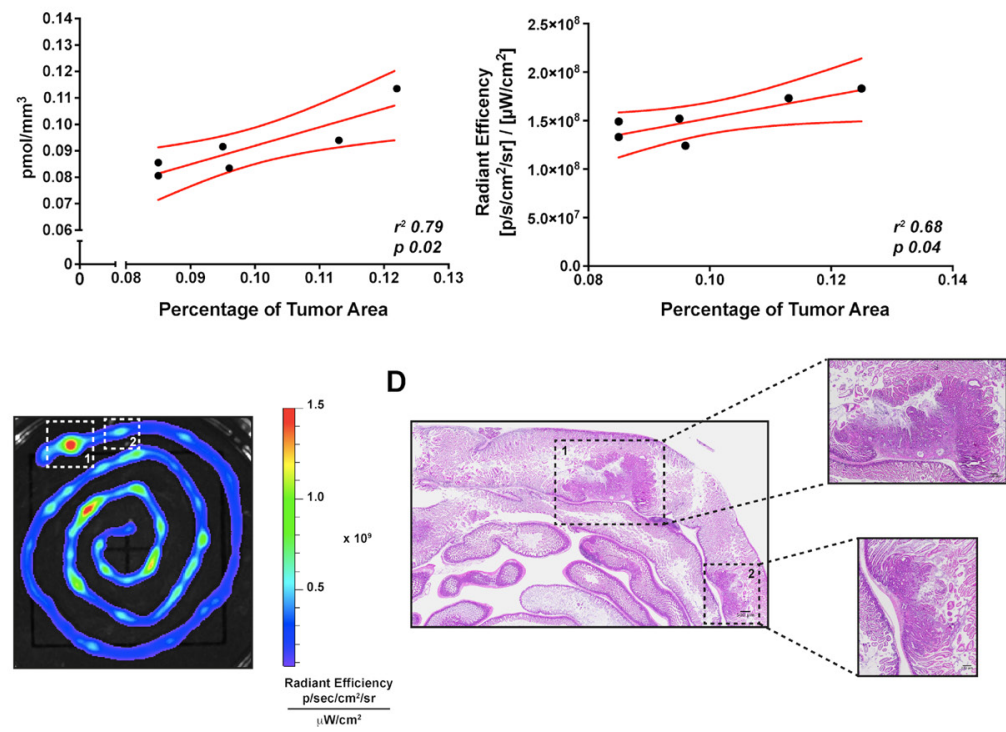

E
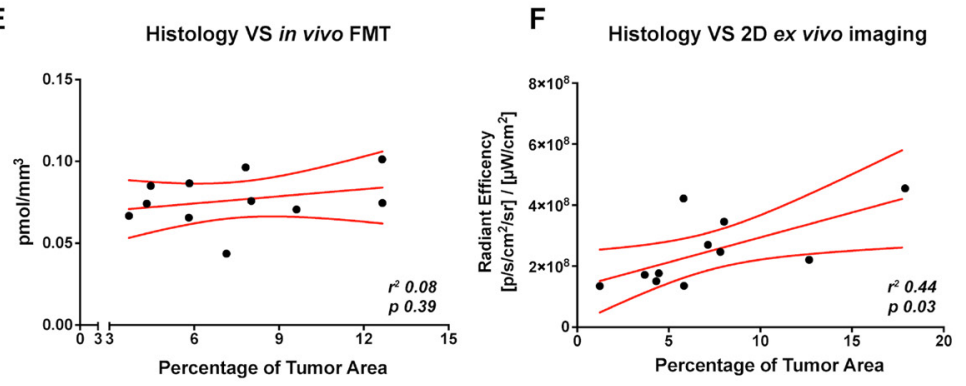

G

H
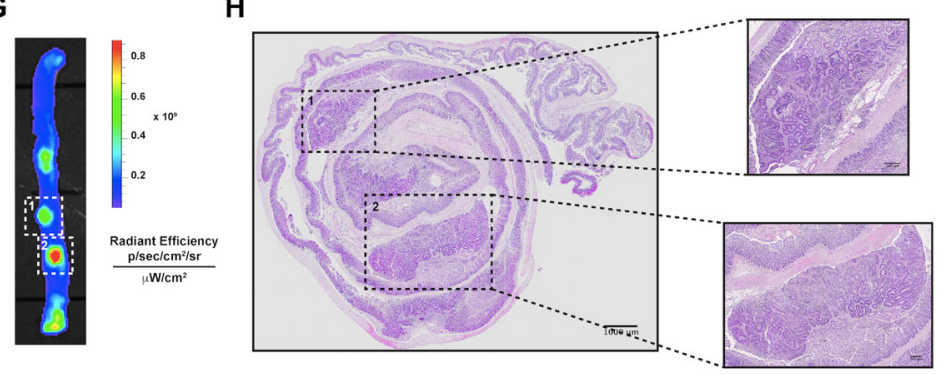

Figure 6: Correlation between in vivo or ex vivo imaging analysis and conventional histology of small intestine and colorectal tumor-bearing $\mathbf{A P C}^{+/ m i n}$ mice. (A) Correlation between FMT IntegriSense750 probe quantification $\left(\mathrm{pmol} / \mathrm{mm}^{3}\right)$ and the percentage of tumor area calculated by histological analysis (as indicated in M\&M) in small intestine tumor-bearing $\mathrm{APC}^{+/ \min }$ mice. Data are presented as Mean and Error $(95 \% \mathrm{CI})$. Linear regression was calculated $\left(r^{2} 0.79\right.$, $p=0.02$ ). (B) Correlation between ex vivo imaging analysis of IntegriSense 750 probe accumulation and the percentage of tumor area calculated by histological analysis (as indicated in M\&M) in small intestine tumor-bearing $\mathrm{APC}^{+/ \min }$ mice. Data are presented as Mean and Error $(95 \% \mathrm{CI})$. Linear regression was calculated $\left(r^{2} 0.68, p=0.04\right)$. (C, D) Representative image of small intestine tumors identified by ex vivo imaging $(\mathrm{C})$ and conventional histology (D). White-dotted line squares in panel $\mathrm{C}$ and black-dotted line squares in panel $\mathrm{D}$ indicate the same neoplastic lesions. Original magnification $10 \times\left(\right.$ E) Correlation between FMT IntegriSense 750 probe quantification $\left(\mathrm{pmol} / \mathrm{mm}^{3}\right)$ and the percentage of tumor area calculated by histological analysis (as indicated in M\&M) in colon tumor-bearing DSS-treated APC ${ }^{+/ m i n}$ mice. Data are presented as Mean and Error $(95 \% \mathrm{CI})$. Linear regression was calculated $\left(r^{2} 0.08, p=0.39\right)$. (F) Correlation between ex vivo imaging analysis of IntegriSense 750 probe accumulation and the percentage of tumor area calculated by histological analysis (as indicated in M\&M) in colon tumor-bearing DSS-treated $\mathrm{APC}^{+ \text {min }}$ mice. Data are presented as Mean and Error $(95 \% \mathrm{CI})$. Linear regression was calculated $\left(r^{2} 0.44, p=0.03\right)$. (G, H) Representative image of colorectal tumors identified by ex vivo imaging (G) and conventional histology $(\mathrm{H})$. White-dotted line squares in panel $\mathrm{G}$ and black-dotted line squares in panel $\mathrm{H}$ indicate the same neoplastic lesions. Original magnification $10 \times$. 
probe IntegriSense (Perkin Elmer) [21] specifically accumulates in cancer tissues compared to healthy mucosa, allowing tumor visualization and the monitoring of neoplastic progression in a genetically-induced mouse model of the small intestine tumor $\left(\mathrm{APC}^{+/ \min }\right)$ as well as in a chemically-induced model of colon cancer (DSStreated $\mathrm{APC}^{+/ \min }$ mice). In addition, data obtained from in vivo FMT detection of IntegriSense correlated with ex vivo imaging acquisitions. Moreover, subsequent immunofluorescence analysis by confocal microscopy revealed a high specificity of IntegriSense signal, showing a precise colocalization with ECM proteins and markers of vascularization.

Collectively, these results strongly support the potential utility of the IntegriSense probe and, more in general, of integrin $\alpha v \beta 3$ expression in studies aimed at evaluating intestinal tumor occurrence and progression.

A

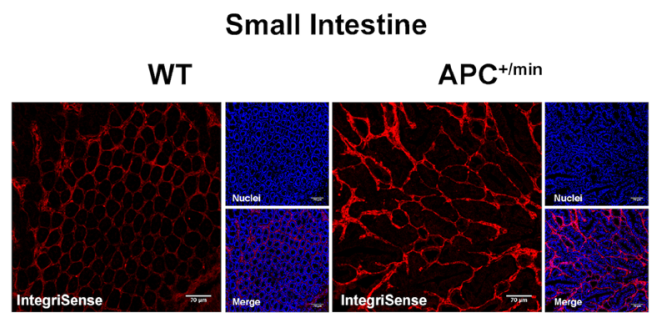

C
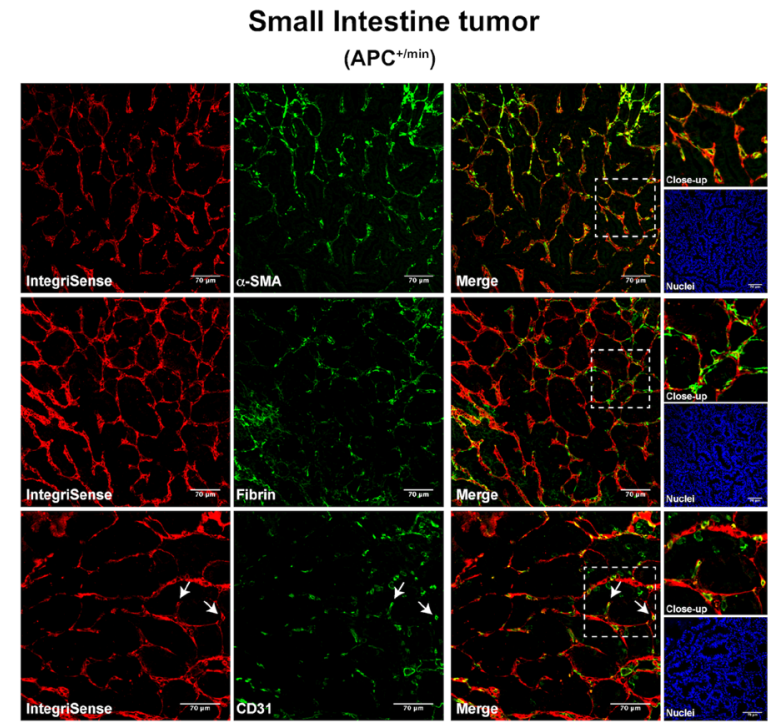

The application of optical molecular imaging techniques in preclinical studies is becoming increasingly important, providing the possibility to investigate tumor progression in small animal models in relatively inexpensive, simple and fast way [4, 5, 7]. Colorectal cancer, a major cause of morbidity and mortality in Western countries, has been investigated in the last years using optical imaging approaches [26, 27]. A variety of NIR-conjugated probes have been generated to recognize specific target involved in CRC progression and eventually evaluate the efficacy of therapeutic treatments. However, the majority of these studies have the limitation of having been performed using transplanted orthotopic or xenograft mouse model of CRC [28-34]. In addition, several fluorescent probes have been already used for the detection of chemically-induced mouse models of CRC, but only for ex vivo validation of tumor occurrence

B

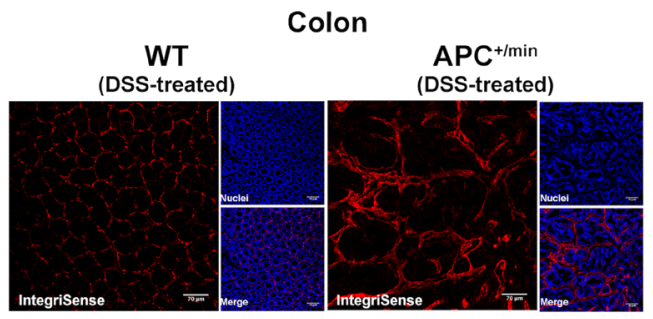

D

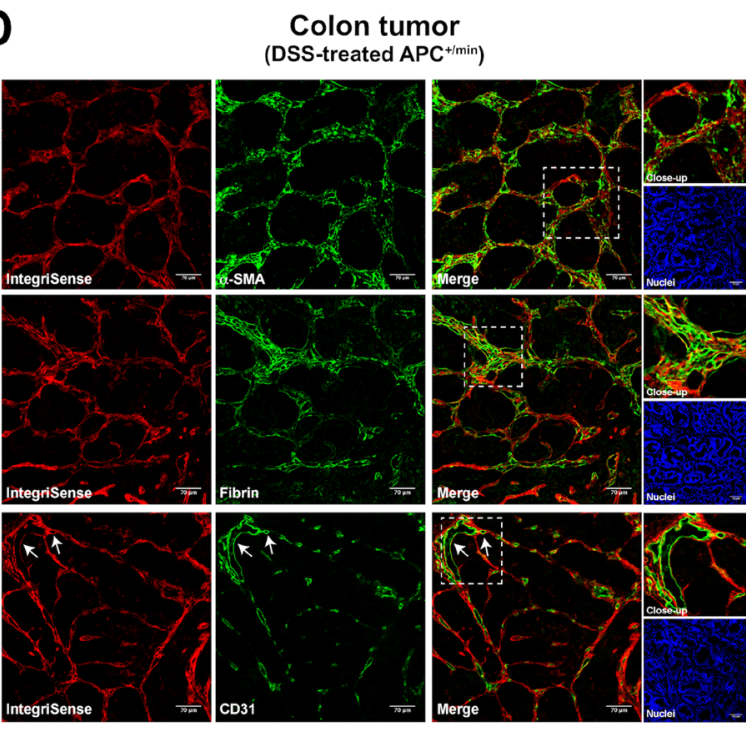

Figure 7: Confocal microscopy analysis of IntegriSense expression in small intestine adenomas and colorectal cancer. (A) Expression of IntegriSense680 in small intestine tissues of 18 weeks old APC ${ }^{+/ m i n}$ mice and age-related WT mice. Red: IntegriSense680, Blue: DAPI (nuclei). Original magnification 20×. (B) Expression of IntegriSense680 in colon tissues of DSS-treated WT and DSS-treated $\mathrm{APC}^{+/ \text {min }}$ mice (as indicated in M\&M). Red: IntegriSense680, Blue: DAPI (nuclei). Original magnification 20×. (C) Colocalization between IntegriSense680 (red) and $\alpha$-SMA, Fibrin and CD31 (green) in small intestine tumors of APC ${ }^{+/ m i n}$ mice. Yellow spots indicate colocalization. White-dotted line squares indicate the close-up. White arrows indicate the colocalization between IntegriSense 680 (red) and the CD $31^{+}$ tumor-associated vessels (green). Blue: DAPI (nuclei). Original magnification 20×. (D) Colocalization between IntegriSense680 (red) and $\alpha$-SMA, Fibrin and CD31 (green) in colorectal tumors of DSS-treated APC ${ }^{+/ m i n}$ mice. Yellow spots indicate colocalization. White-dotted line squares indicate the close-up. White arrows indicate the colocalization between IntegriSense680 (red) and the CD $31^{+}$tumor-associated vessels (green). Blue: DAPI (nuclei). Original magnification 20×. 
or metastatic dissemination [35, 36]. More recently, a protease-activatable NIRF imaging probe has been used for the FMT imaging of azoxymethane (AOM)-induced colonic tumors, presenting anyway some limitations as a valid non-endoscopic method for cancer detection [37]. Of note, the advantage of FMT versus conventional 2D optical imaging has been already discussed [9] and recently applied for the detection and quantification of inflammation in a mouse model of inflammatory bowel disease [38].

Although integrin $\alpha v \beta 3$ has been already used to visualize transplanted mouse model of CRC $[28,30]$, to our knowledge this is the first study where its detection by optical in vivo imaging has been used for the non-invasive evaluation of genetic or chemically-induced mouse model of intestinal tumor. In addition, the use of fluorescent molecular tomography (FMT) technique, combined with the $750 \mathrm{~nm}$ wavelength NIRF probe, allows a more precise three-dimensional and deep localization of the signal and the quantification of the fluorescent probe within the outlined regions of interest. Anyway, the anatomical resolution of optical in vivo imaging techniques is quite limited due to light scattering and absorption by surrounding tissues: in the present study, two different
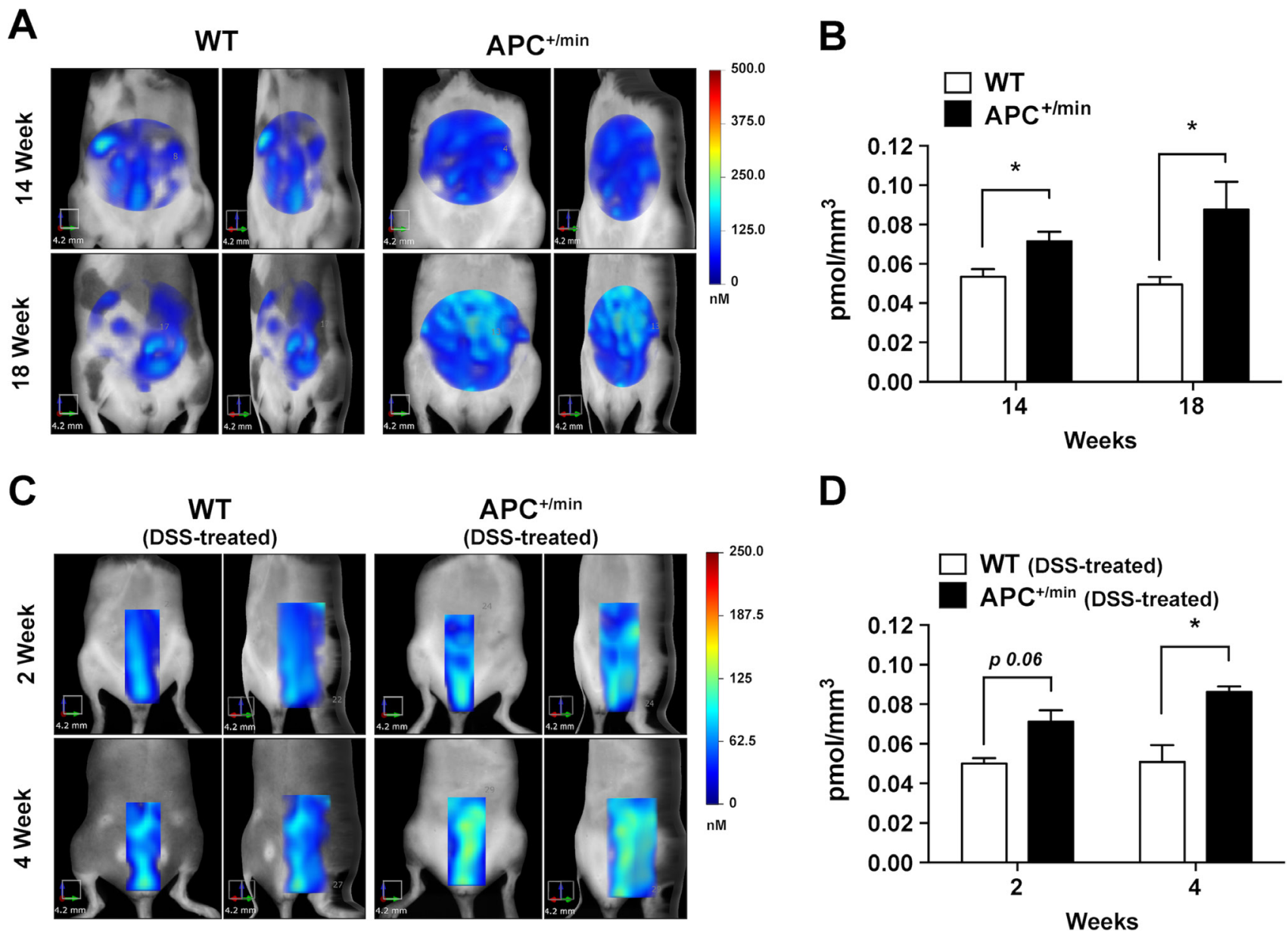

Figure 8: In vivo FMT monitoring of small intestine adenomas and colorectal tumor growth. (A) In vivo Fluorescent Molecular Tomography (FMT) analysis of IntegriSense750 accumulation in the small intestine of APC ${ }^{+/ m i n}$ and WT mice. Mice were acquired at 14 and 18 weeks of age. Region of interest (ROI) was tri-dimensionally defined to outline the small intestine. The colorbar shows the concentration (in $\mathrm{nM}$ ) of the IntegriSense750 probe. (B) FMT quantification of IntegriSense750 probe accumulation in the small intestine of $\mathrm{APC}^{+/ \min }$ and WT mice. Mice were acquired at 14 and 18 weeks of age. The total amount of probe within the ROI (in pmoles) was calculated as indicated in the M\&M. The amount of pmoles of the probe was normalized based on the volume $\left(\mathrm{mm}^{3}\right)$ of the ROI, after adjustment using the statistically derived threshold value. Data are presented as mean \pm SEM. Multiple $t$ test, ${ }^{*} p<0.05$ (C) In vivo Fluorescent Molecular Tomography (FMT) analysis of IntegriSense 750 accumulation in the colon of the DSS-treated APC ${ }^{+/ m i n}$ and DSS-treated WT mice. Mice were acquired at week 2 and 4 after the end of the DSS administration. Region of interest (ROI) was tri-dimensionally defined to outline the colon. The colorbar shows the concentration (in nM) of the IntegriSense750 probe. (D) FMT quantification of IntegriSense 750 probe accumulation in the colon of DSS-treated APC ${ }^{+/ m i n}$ and WT mice. Mice were acquired at week 2 and 4 after the end of the DSS administration. The total amount of probe within the ROI (in pmoles) was calculated as indicated in the M\&M. The amount of pmoles of the probe was normalized based on the volume $\left(\mathrm{mm}^{3}\right)$ of the ROI, after adjustment using the statistically derived threshold value. Data are presented as mean \pm SEM. Multiple $t$ test with Holm-Sidak multiple comparison, ${ }^{*} p<0.05$. 
ROIs were used in order to isolate as much as possible the small intestine (located in the anterior region of the abdominal cavity and identified with an ellipsoid ROI) and the colon (located in the posterior region of the abdominal cavity, in cranio-caudal direction, and identified with a cylindrical ROI). For this reason, ex vivo optical imaging was used as a confirmation of the signal detected by in vivo FMT imaging. While a clear correlation between in vivo and ex vivo imaging was found for the small intestine, a poor but still significant relationship between in vivo and ex vivo analysis was found for the colon. This difference can be explained by considering the deep position of the colon in the abdominal cavity and the consequent effect of scattering and absorption by surrounding tissues affecting both excitation and emission light, that eventually limits the specificity of the results. These aspects have to be carefully considered, suggesting cautions in the interpretation of in vivo imaging results.

We also evaluated the feasibility of IntegriSense probe to distinguish mouse models with a different tumor load. For this purpose, $\mathrm{APC}^{+/ \mathrm{min}}$ mice were previously breed with $\mathrm{CX}_{3} \mathrm{CR}^{+/-}$and $\mathrm{CX}_{3} \mathrm{CR} 1^{-/}$mice. $\mathrm{CX}_{3} \mathrm{CR} 1$ is considered a marker for resident intestinal macrophages, which play a central role in regulating inflammation, and its absence has been correlated with dysregulated inflammatory response, tissue damage and higher tumor occurrence [18-20, 22, 39]. Our data, in line with the literature, showed that in the $\mathrm{APC}^{+/ m i n}$ mouse model of small intestine carcinogenesis, the accumulation of IntegriSense probe was slightly but significantly higher

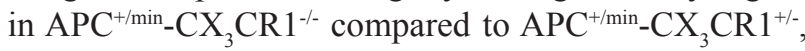
confirming the protective effect of $\mathrm{CX}_{3} \mathrm{CR} 1$ in intestinal inflammation.

Furthermore, we compared optical imaging results with conventional histological analysis. Even if a correlation between histology and optical imaging analysis was found (especially in the small intestine carcinogenesis model), this result needs to be carefully discussed. In fact, while optical imaging allows the visualization and analysis of the entire tissue, histology is limited by the physical sectioning of the sample. This sectioning could result in the impossibility to have all tumors in the same slide, especially when bigger tissues and small lesions are considered (as indeed occurs in the $\mathrm{APC}^{+/ \min }$ model of small intestine carcinogenesis). Of note, this consideration could also explain the fact that the slightly difference in small intestine tumor formation between $\mathrm{APC}^{+/ \mathrm{min}_{-}}$ $\mathrm{CX}_{3} \mathrm{CR}^{-/-}$and $\mathrm{APC}^{+/ m i n}{ }_{-} \mathrm{CX}_{3} \mathrm{CR}^{+/-}$detected by both in vivo and ex vivo optical imaging was not confirmed by histological analysis (data not shown). In this context, optical imaging and histology can be considered as two complementary, rather than overlapping, techniques, able to provide different features of the same sample.

The role of integrins in cancer progression has been extensively described, being involved in tumor cell migration, invasion and control of angiogenesis, lymphangiogenesis and inflammation [10, 11]. Among integrins, $\alpha v \beta 3$ is probably the most strongly involved in the regulation of angiogenesis [11, 13, 40]. It has been reported that, differently from the quiescent endothelium, integrin $\alpha v \beta 3$ is highly expressed by tumor-associated vessels, possibly mediating the interaction between endothelial cells and provisional matrix protein, such as vitronectin, fibrinogen and proteolized collagen $[11,15$, $41,42]$. These observations are in line with our confocal acquisitions, showing a colocalization between the IntegriSense probe and the matrix protein $(\alpha-\mathrm{SMA}$ and fibrin) as well as the $\mathrm{CD} 31^{+}$tumor-associated vessels.

The expression of integrin $\alpha v \beta 3$ correlated with disease progression in various type of cancer, including breast, pancreatic and prostate cancer and glioblastomas [43-49]. Given its role in cancer progression and neoangiogenesis processes, it is not surprising that integrin $\alpha v \beta 3$ represents an interesting target for the visualization and treatment of a variety of tumors [15, 40, 50-56]. Coupling integrin $\alpha v \beta 3$ antagonists or antibodies (LM609) to paramagnetic contrast agents or radionuclides provided the detection of vascularization in experimental tumor models [15, 56-58]. In addition, combination of ${ }^{18} \mathrm{~F}$-galacto-RGD and PET allowed the quantification of integrin $\alpha v \beta 3$ expression in murine tumor models and in cancer patients [59]. In CRC, it has been demonstrated that vascular expression of integrin $\alpha v \beta 3$ correlated with the presence of liver metastasis, reduced relapse-free interval and patients' overall survival [12]. In addition, treatment with an integrin $\alpha v \beta 3$ antagonist resulted in prolonged survival in an orthotopic murine model of colon cancer liver metastasis, with a reduction of vessels in liver metastasis, an increase in endothelial cell apoptosis and a significant decrease in pericyte coverage [60]. Moreover, optical in vivo imaging detection of integrin $\alpha v \beta 3$ has been successfully used in combination with $\mathrm{PET} / \mathrm{CT}$ analysis for the visualization of subcutaneous and orthotopic transplanted mouse model of CRC [28]. Accordingly, our in vivo, ex vivo and confocal data showed that integrin $\alpha v \beta 3$ is already expressed by intestinal tissue, and its expression strongly increased in tumors. These observations confirmed the role of integrin $\alpha v \beta 3$ in intestinal carcinogenesis, additionally showing that its expression could be used for the early tumor detection by FMT in preclinical mouse models. In fact, our results demonstrated that a higher IntegriSense accumulation was already detectable after 14 weeks of age in small intestine adenomas-bearing $\mathrm{APC}^{+/ \min }$ mice and 2 weeks after DSS treatment in colorectal cancer-bearing $\mathrm{APC}^{+/ m i n}$ mice. Of note, the signal slightly increased in time, indicating that IntegriSense detection can be used to monitor tumor progression both in the small and large intestine. These observations raise the possibility of using integrin $\alpha \mathrm{v} \beta 3$ imaging for early detection of human CRC. Of course, the application of fluorescent reporter in human is limited to intra-operative imaging-guided surgery, thus the integrin 
av $\beta 3$ imaging should be approached with MRI or PET techniques.

In conclusion, our results support the use of integrin $\alpha v \beta 3$ detection probe for the in vivo FMT and ex vivo 2D-imaging detection of tumor in preclinical mouse models of intestinal carcinogenesis. In particular, FMT technique, together with the use of NIRF probe, increases the specificity of tumor detection compared to 2D conventional optical imaging methods, ameliorating the anatomical resolution. Combining integrin $\alpha v \beta 3$ FMT application with other imaging techniques, such as microCT or MRI, could improve the specificity and sensitivity of intestinal cancer visualization, laying the foundations for the potential use of integrin $\alpha v \beta 3$ expression for the early detection of intestinal tumors in humans.

\section{MATERIALS AND METHODS}

\section{Animal models}

Procedures involving animals and their care conformed to institutional guidelines in compliance with national (4D.L. N.116, G.U., suppl. 40, 18-2-1992) and international law and policies (European Economic Community Council Directive 2010/63/EU, OJ L 276/33, 22.09.2010; National Institutes of Health Guide for the Care and Use of Laboratory Animals, U.S. National Research Council, 2011). All efforts were made to minimize the number of animals used and their suffering. All mice were on C57/B6 background. We compared $\mathrm{APC}^{+/ \text {min }}{ }_{-} \mathrm{CX}_{3} \mathrm{CR} 1^{+/ g f p}$ and $\mathrm{APC}^{+/ \text {min }}{ }_{-} \mathrm{CX}_{3} \mathrm{CR} 1^{\text {gfp/gfp }}$ mice (indicated as $\mathrm{APC}^{+/ m i n}$, when the $\mathrm{CX}_{3} \mathrm{CR} 1$ status were not considered) with $\mathrm{CX}_{3} \mathrm{CR} 1^{+/ \mathrm{gfp}}$ and $\mathrm{CX}_{3} \mathrm{CR} 1^{\mathrm{gfp} / \mathrm{gfp}}$ (indicated as WT, when the $\mathrm{CX}_{3} \mathrm{CR} 1$ status were not considered). Since GFP expression was not considered in this study, we indicated heterozygous $\mathrm{CX}_{3} \mathrm{CR} 1^{+/ g f p}$ mice as $\mathrm{CX}_{3} \mathrm{CR} 1^{+/}$ and knock-out $\mathrm{CX}_{3} \mathrm{CR} 1^{\text {gfpgfp }}$ mice as $\mathrm{CX}_{3} \mathrm{CR} 1^{-}$. Mice were maintained in a specific-pathogen free facility, and given ad libitum access to food and water. Where indicated, mice were feed with the specific AIN76A, alfalfa-free rodent diet (Mucedola srl).

\section{RNA extraction and quantitative real-time PCR}

RNA was extracted from adenomas or corresponding healthy mucosa independently. Samples were homogenized in TRIzol (Ambion) using Tissue Lyser II (Quiagen). A quantity amounting to $1 \mu \mathrm{g}$ total RNA was reverse transcribed using the High-Capacity cDNA Archive kit (Applied Biosystems), according to manufacturer's instruction. cDNA was analyzed by quantitative real-time PCR, performed on CFX96 Touch ${ }^{\mathrm{TM}}$ Real-time PCR detection system (BioRad), using Fast SYBR Green (Applied Biosystems). Actin gene was used as internal control. The sequences of primers are as follow:

\section{Integrin $\beta 3$}

Forward: 5'-CCAGGCTCCTATGGAGACAC-3', Reverse: 5'-CCCCGGTTGAACTTCTTACA-3'

\section{Integrin $\alpha \mathrm{V}$}

Forward: 5'-GCTCATGCTTTCTATCCCAC-3'
Reverse: 5'- TTCATCGGGTTTCCAAGGTC-3',

Actin

Forward: 5'-CCCAAGGCCAACCGCGAGAAG-3' Reverse: 5'-GTCCCGGCCAGCCAGGTCCAG-3'

\section{Histological analysis}

Tissues were harvested, cleaned from the luminal content, longitudinally opened and rolled up transversely (Swiss roll). Tissues were then fixed in $4 \%$ paraformaldehyde (PFA) overnight $(\mathrm{O} / \mathrm{N})$ at $4^{\circ} \mathrm{C}$ and paraffin-embedded. To evaluate the histologic architecture of the tissue and the percentage of the tumor area over the total tissue, $2-\mu \mathrm{m}$ thick sections were cut and stained with hematoxylin and eosin (H\&E stain). Slides were scanned with VS120-S5 Virtual Slide System (Olympus) and analyzed with OlyVIA Software (Olympus): subsequently, we calculated the percentage of global tumor area, by summing the dimensions of the multiple neoplastic lesions and dividing them by the dimension of the entire tissue section.

The following formula was used: Percentage of tumor area: (Global dimension of the neoplastic lesions $\times$ 100)/Dimension of the entire tissue section

\section{Fluorescent molecular tomography (FMT)}

Fluorescent molecular tomography (FMT) was performed using FMT2000 system (Perkin Elmer). Briefly, animals were fed with AIN76A, alfalfa-free rodent diet (Mucedola srl) for at least 2 weeks before the acquisition in order to reduce autofluorescence background. $24 \mathrm{~h}$ before imaging session, mice were shaved to avoid the interference of the fur and IV injected with $0.08 \mathrm{nmol} / \mathrm{g}$ of body weight of IntegriSense750 probe (Perkin Elmer) [21]. Prior to the imaging, mice were anesthetized with a mixture of ketamine and xylazine and positioned in a dedicated imaging cassette. The imaging cassette was adjusted to the proper depth to gently restrain the mice. Mice were inserted in supine position into the heated docking system $\left(\sim 37^{\circ} \mathrm{C}\right)$ into the FMT imaging chamber and trans-illuminated with $750 \mathrm{~nm}$ near infrared (NIR) laser. The entire acquisition procedure took approximately 6-8 minute per mouse. The collected images were reconstructed and analysed using TrueQuant3.1 software (Perkin Elmer). Three-dimensional regions of interest (ROI) were designed to identify the small intestine and 
the colon. Threshold was applied equal to the $40 \%$ of the mean fluorescence (in $\mathrm{nM}$ ) of the control mice. The total amount of probe within the ROI (in pmoles) was automatically calculated relative to the internal standard generated with a known concentration of the appropriate NIR dye, following manufacturer's instruction. The amount of pmoles of the probe was normalized based on the volume $\left(\mathrm{mm}^{3}\right)$ of ROI, after adjustment using the statistically derived threshold value.

\section{IVIS Lumina III ex vivo imaging}

Ex vivo imaging was performed using IVIS Lumina III system (Perkin Elmer). Briefly, after in vivo FMT analysis, mice were sacrificed, the organs collected and acquired using the following parameters: excitation filter $740 \mathrm{~nm}$, emission filter $790 \mathrm{~nm}$, binning 4 or 8, f/Stop 2 . Collected images were analysed using Living Image 4.3.1 software (Perkin Elmer): ROIs were designed in order to appropriately select each organs and radiant efficiency calculated.

\section{Immunofluorescence}

For immunofluorescence staining, tissues were harvested and cleaned from the luminal content. Subsequently, tissues were fixed in $4 \% \mathrm{PFA}, \mathrm{O} / \mathrm{N}$ at $4^{\circ} \mathrm{C}$, dehydrated in $40 \%$ Sucrose in $\mathrm{PBS}^{-/}$(without Calcium and Magnesium) $\mathrm{O} / \mathrm{N}$ at $4^{\circ} \mathrm{C}$ and finally embedded in optimum cutting temperature compound (OCT, Diapath). 6- $\mu \mathrm{m}$ thick frozen section were cut with cryostat. For immunofluorescence staining, sections were incubated with primary antibodies in $\mathrm{PBS}^{+/+}$(with Calcium and Magnesium) containing 2\% Bovine Serum Albumin (BSA), 5\% Normal Goat Serum, 0.1\% Triton X-100 for $1 \mathrm{~h}$ at room temperature. The following antibodies were used: rabbit polyclonal anti-fibrin(ogen) (Dako); mouse monoclonal anti $\alpha$-SMA-Cy3 (Sigma-Aldrich); Hamster monoclonal anti-PECAM1 (CD31) (Millipore). Sections were then washed 3 times for 5 minutes in $\mathrm{PBS}^{+/+}, 0.2 \%$ BSA, 0.05\% Tween-20 and incubated with Alexa Fluor (532, 594, 633)-conjugated species-specific, crossadsorbed, detection antibodies (Molecular Probes) at room temperature for $1 \mathrm{~h}$. After 4 washing in $\mathrm{PBS}^{+/+}, 0.2 \%$ BSA, $0.05 \%$ Tween-20, cell nuclei were counterstained with DAPI (300 nM, Invitrogen). For IntegriSense detection, mice were injected IV with IntegriSense680 (Perkin Elmer) [21]: after 24 h, mice were sacrificed and tissues harvested and processed as previously described. Tissues were finally mounted with FluorPreserve Reagent (Calbiochem) and acquired with a Leica SP8 STED3X confocal microscope, using a $20 \times /$ NA 0.75 multiimmersion objective (Leica). Samples were excited with a 405 Diode CW laser and with a tunable pulsed White Light Laser. Emission filter bandwidths were set up in order to avoid any possible spectral overlap between fluorophores. Collected images were then processed with Fiji ImageJ (National Institutes of Health).

\section{Statistical analysis}

Statistical analysis was performed using GraphPad Prism 6 (GraphPad software). Student's $t$ test, multiple student's $t$ test with Holm-Sidak multiple comparison test and linear regression analysis were used, as indicated in the figure legends. A $p$ value $<0.05$ was considered as statistically significant.

\section{Abbreviations}

FMT: Fluorescent Molecular Tomography; APC: Adenomatous Polyposis Coli; CRC: Colorectal cancer; NIR: Near-InfraRed; ROI: Region of Interest; ECM: Extracellular Matrix; DSS: Dextran Sulfate-Sodium.

\section{Author contributions}

M.G., A.R., E.M., carried out experiments; E.M. designed and supervised the experiments; E.M., M.G., A.P., G.C., M.A., D.A. wrote and supervised the manuscript; A.P., G.C., M.A. acquired funding for the study.

\section{ACKNOWLEDGMENTS}

We thank Dr. Diego Morone for useful scientific discussions.

\section{CONFLICTS OF INTEREST}

Authors have no conflicts of interest to disclose.

\section{FUNDING}

This work was supported by an ERC grant to Prof. A. Mantovani from the European Research Council (ERC - Grant number 669415 - PHII) and by IG grant from the Italian Association for Cancer Research (AIRC).

\section{REFERENCES}

1. Jemal A, Siegel R, Xu J, Ward E. Cancer statistics. CA Cancer J Clin. 2010; 60:277-300. https://doi.org/10.3322/ caac. 20073.

2. Becker C, Fantini MC, Neurath MF. High resolution colonoscopy in live mice. Nat Protoc. 2006; 1:2900-2904. https://doi.org/10.1038/nprot.2006.446.

3. Ahn SB, Han DS, Bae JH, Byun TJ, Kim JP, Eun CS. The Miss Rate for Colorectal Adenoma Determined by QualityAdjusted, Back-to-Back Colonoscopies. Gut Liver. 2012; 6:64-70. https://doi.org/10.5009/gnl.2012.6.1.64. 
4. Hickson J. In vivo optical imaging: preclinical applications and considerations. Urol Oncol. 2009; 27:295-297. https:// doi.org/10.1016/j.urolonc.2008.10.030.

5. Leblond F, Davis SC, Valdés PA, Pogue BW. Pre-clinical whole-body fluorescence imaging: Review of instruments, methods and applications. J Photochem Photobiol B. 2010; 98:77-94. https://doi.org/10.1016/j.jphotobiol.2009.11.007.

6. de Jong M, Essers J, van Weerden WM. Imaging preclinical tumour models: improving translational power. Nat Rev Cancer. 2014; 14:481-493. https://doi.org/10.1038/nrc3751.

7. Martelli C, Lo Dico A, Diceglie C, Lucignani G. Ottobrini L. Optical imaging probes in oncology. Oncotarget. 2016; 7:48753-48787. https://doi.org/10.18632/oncotarget.9066.

8. Weissleder R. Ntziachristos V. Shedding light onto live molecular targets. Nat Med. 2003; 9:123-128. https://doi. org/10.1038/nm0103-123.

9. Stuker F, Ripoll J, Rudin M. Fluorescence molecular tomography: principles and potential for pharmaceutical research. Pharmaceutics. 2011; 3:229-274. https://doi. org/10.3390/pharmaceutics3020229.

10. Rathinam R, Alahari SK. Important role of integrins in the cancer biology. Cancer Metastasis Rev. 2010; 29:223-237. https://doi.org/10.1007/s10555-010-9211-x.

11. Desgrosellier JS, Cheresh DA. Integrins in cancer: biological implications and therapeutic opportunities. Nat Rev Cancer. 2010; 10:9-22. https://doi.org/10.1038/ $\operatorname{nrc} 2748$

12. Vonlaufen A, Wiedle G, Borisch B, Birrer S, Luder P, Imhof BA. Integrin alpha(v)beta(3) expression in colon carcinoma correlates with survival. Mod Pathol. 2001; 14:1126-1132. https://doi.org/10.1038/modpathol.3880447.

13. Demircioglu F. Hodivala-Dilke K. $\alpha v \beta 3$ Integrin and tumour blood vessels-learning from the past to shape the future. Curr Opin Cell Biol. 2016; 42:121-127. https://doi. org/10.1016/j.ceb.2016.07.008.

14. Axelsson R, Bach-Gansmo T, Castell-Conesa J, McParland BJ, Study G. An open-label, multicenter, phase 2a study to assess the feasibility of imaging metastases in late-stage cancer patients with the alpha $\mathrm{v}$ beta 3 -selective angiogenesis imaging agent 99mTc-NC100692. Acta Radiol. 2010; 51:40-46. https://doi.org/10.3109/02841850903273974.

15. Danhier F, Le Breton A, Préat V. RGD-based strategies to target alpha(v) beta(3) integrin in cancer therapy and diagnosis. Mol Pharm. 2012; 9:2961-2973. https://doi. org/10.1021/mp3002733.

16. McCart AE, Vickaryous NK. Silver A. Apc mice: models, modifiers and mutants. Pathol Res Pract. 2008; 204:479490. https://doi.org/10.1016/j.prp.2008.03.004.

17. Medina-Contreras O, Geem D, Laur O, Williams IR, Lira SA, Nusrat A, Parkos CA, Denning TL. CX3CR1 regulates intestinal macrophage homeostasis, bacterial translocation, and colitogenic Th17 responses in mice. J Clin Invest. 2011; 121:4787-4795. https://doi.org/10.1172/JCI59150.
18. Erreni M, Siddiqui I, Marelli G, Grizzi F, Bianchi P, Morone D, Marchesi F, Celesti G, Pesce S, Doni A, Rumio C, Roncalli MG, Laghi L, et al. The Fractalkine-Receptor Axis Improves Human Colorectal Cancer Prognosis by Limiting Tumor Metastatic Dissemination. J Immunol. 2016; 196:902-914. https://doi.org/10.4049/jimmunol.1501335.

19. Marelli G, Belgiovine C, Mantovani A, Erreni M. Allavena P. Non-redundant role of the chemokine receptor CX3CR1 in the anti-inflammatory function of gut macrophages. Immunobiology. 2017; 222:463-472. https://doi. org/10.1016/j.imbio.2016.07.013.

20. Marelli G, Erreni M, Anselmo A, Taverniti V, Guglielmetti S, Mantovani A, Allavena P. Heme-oxygenase-1 production by intestinal $\mathrm{CX} 3 \mathrm{CR} 1(+)$ macrophages helps to resolve inflammation and prevents carcinogenesis. Cancer Res. 2017; 77:4472-85. https://doi.org/10.1158/0008-5472.CAN-16-2501.

21. Kossodo S, Pickarski M, Lin SA, Gleason A, Gaspar R, Buono C, Ho G, Blusztajn A, Cuneo G, Zhang J, Jensen J, Hargreaves R, Coleman P, et al. Dual in vivo quantification of integrin-targeted and protease-activated agents in cancer using fluorescence molecular tomography (FMT). Mol Imaging Biol. 2010; 12:488-499. https://doi.org/10.1007/ s11307-009-0279-z.

22. Mowat AM, Bain CC. Mucosal macrophages in intestinal homeostasis and inflammation. J Innate Immun. 2011; 3:550-564. https://doi.org/10.1159/000329099.

23. Chassaing B, Aitken JD, Malleshappa M, Vijay-Kumar M. Dextran sulfate sodium (DSS)-induced colitis in mice. Curr Protoc Immunol. 2014; 104:15.25. https://doi. org/10.1002/0471142735.im1525s104.

24. Tanaka T, Kohno H, Suzuki R, Hata K, Sugie S, Niho N, Sakano K, Takahashi M, Wakabayashi K. Dextran sodium sulfate strongly promotes colorectal carcinogenesis in Apc(Min/+) mice: inflammatory stimuli by dextran sodium sulfate results in development of multiple colonic neoplasms. Int J Cancer. 2006; 118:25-34. https://doi. org/10.1002/ijc.21282.

25. O'Connor JP, Aboagye EO, Adams JE, Aerts HJ, Barrington SF, Beer AJ, Boellaard R, Bohndiek SE, Brady M, Brown G, Buckley DL, Chenevert TL, Clarke LP, et al. Imaging biomarker roadmap for cancer studies. Nat Rev Clin Oncol. 2017; 14:169-186. https://doi.org/10.1038/ nrclinonc.2016.162.

26. Sheth RA, Mahmood U. Optical molecular imaging and its emerging role in colorectal cancer. Am J Physiol Gastrointest Liver Physiol. 2010; 299:G807-20. https:/doi. org/10.1152/ajpgi.00195.2010.

27. Mahmood U. Optical molecular imaging approaches in colorectal cancer. Gastroenterology. 2010; 138:419-422. https://doi.org/10.1053/j.gastro.2009.12.014.

28. Nahrendorf M, Keliher E, Marinelli B, Waterman P, Feruglio PF, Fexon L, Pivovarov M, Swirski FK, Pittet MJ, Vinegoni C, Weissleder R. Hybrid PET-optical imaging 
using targeted probes. Proc Natl Acad Sci U S A. 2010; 107:7910-7915. https://doi.org/10.1073/pnas.0915163107.

29. Cohen G, Lecht S, Arien-Zakay H, Ettinger K, Amsalem O, Oron-Herman M, Yavin E, Prus D, Benita S, Nissan A, Lazarovici P. Bio-imaging of colorectal cancer models using near infrared labeled epidermal growth factor. PLoS One. 2012; 7:e48803. https://doi.org/10.1371/journal. pone.0048803.

30. Verbeek FP, van der Vorst JR, Tummers QR, Boonstra $\mathrm{MC}$, de Rooij KE, Löwik CW, Valentijn AR, van de Velde CJ, Choi HS, Frangioni JV, Vahrmeijer AL. Nearinfrared fluorescence imaging of both colorectal cancer and ureters using a low-dose integrin targeted probe. Ann Surg Oncol. 2014; 21:S528-37. https://doi.org/10.1245/ s10434-014-3524-x.

31. Paudyal B, Paudyal P, Shah D, Tominaga H, Tsushima Y, Endo K. Detection of vascular endothelial growth factor in colon cancer xenografts using bevacizumab based near infrared fluorophore conjugate. J Biomed Sci. 2014; 21:35. https://doi.org/10.1186/1423-0127-21-35.

32. Tiernan JP, Ingram N, Marston G, Perry SL, Rushworth JV, Coletta PL, Millner PA, Jayne DG, Hughes TA. CEAtargeted nanoparticles allow specific in vivo fluorescent imaging of colorectal cancer models. Nanomedicine (Lond). 2015; 10:1223-1231. https://doi.org/10.2217/nnm.14.202.

33. Kazmierczak PM, Burian E, Eschbach R, HirnerEppeneder H, Moser M, Havla L, Eisenblätter M, Reiser MF, Nikolaou K, Cyran CC. Monitoring Cell Death in Regorafenib-Treated Experimental Colon Carcinomas Using Annexin-Based Optical Fluorescence Imaging Validated by Perfusion MRI. PLoS One. 2015; 10:e0138452. https://doi.org/10.1371/journal.pone.0138452.

34. Choi YJ, Oh SG, Singh TD, Ha JH, Kim DW, Lee SW, Jeong SY, Ahn BC, Lee J, Jeon YH. Visualization of the Biological Behavior of Tumor-Associated Macrophages in Living Mice with Colon Cancer Using Multimodal Optical Reporter Gene Imaging. Neoplasia. 2016; 18:133-141. https://doi.org/10.1016/j.neo.2016.01.004.

35. Marten K, Bremer C, Khazaie K, Sameni M, Sloane B, Tung $\mathrm{CH}$, Weissleder R. Detection of dysplastic intestinal adenomas using enzyme-sensing molecular beacons in mice. Gastroenterology. 2002; 122:406-414.

36. Yoon SM, Myung SJ, Ye BD, Kim IW, Lee NG, Ryu YM, Park K, Kim K, Kwon IC, Park YS, Park CS, Moon DH, $\mathrm{Kim} \mathrm{DH}$, et al. Near-infrared fluorescence imaging using a protease-specific probe for the detection of colon tumors. Gut Liver. 2010; 4:488-497. https://doi.org/10.5009/ gnl.2010.4.4.488.

37. Ding S, Blue RE, Moorefield E, Yuan H, Lund PK. Ex Vivo and In Vivo Noninvasive Imaging of Epidermal Growth Factor Receptor Inhibition on Colon Tumorigenesis Using Activatable Near-Infrared Fluorescent Probes. Mol Imaging. 2017; 16:1536012117729044. https://doi. org/10.1177/1536012117729044.
38. Ding S, Blue RE, Morgan DR, Lund PK. Comparison of multiple enzyme activatable near-infrared fluorescent molecular probes for detection and quantification of inflammation in murine colitis models. Inflamm Bowel Dis. 2014; 20:363-377. https://doi.org/10.1097/01. MIB.0000440612.98950.79.

39. Erreni M, Mantovani A, Allavena P. Tumor-associated Macrophages (TAM) and Inflammation in Colorectal Cancer. Cancer Microenviron. 2011; 4:141-154. https://doi. org/10.1007/s12307-010-0052-5.

40. Kang W, Svirskis D, Sarojini V, McGregor AL, Bevitt $\mathrm{J}, \mathrm{Wu} \mathrm{Z}$. Cyclic-RGDyC functionalized liposomes for dual-targeting of tumor vasculature and cancer cells in glioblastoma: An in vitro boron neutron capture therapy study. Oncotarget. 2017; 8:36614-36627. https://doi. org/10.18632/oncotarget.16625.

41. Davis GE. Affinity of integrins for damaged extracellular matrix: alpha v beta 3 binds to denatured collagen type I through RGD sites. Biochem Biophys Res Commun. 1992; 182:1025-1031.

42. Brooks PC, Clark RA, Cheresh DA. Requirement of vascular integrin alpha $v$ beta 3 for angiogenesis. Science. 1994; 264:569-571.

43. Hosotani R, Kawaguchi M, Masui T, Koshiba T, Ida J, Fujimoto K, Wada M, Doi R, Imamura M. Expression of integrin alphaVbeta3 in pancreatic carcinoma: relation to MMP-2 activation and lymph node metastasis. Pancreas. 2002; 25:e30-5.

44. Zhao Y, Bachelier R, Treilleux I, Pujuguet P, Peyruchaud $\mathrm{O}$, Baron R, Clément-Lacroix P, Clézardin P. Tumor alphavbeta3 integrin is a therapeutic target for breast cancer bone metastases. Cancer Res. 2007; 67:5821-5830. https:// doi.org/10.1158/0008-5472.CAN-06-4499.

45. McCabe NP, De S, Vasanji A, Brainard J, Byzova TV. Prostate cancer specific integrin alphavbeta3 modulates bone metastatic growth and tissue remodeling. Oncogene. 2007; 26:6238-6243. https://doi.org/10.1038/ sj.onc. 1210429.

46. Desgrosellier JS, Barnes LA, Shields DJ, Huang M, Lau SK, Prévost N, Tarin D, Shattil SJ, Cheresh DA. An integrin alpha(v)beta(3)-c-Src oncogenic unit promotes anchorageindependence and tumor progression. Nat Med. 2009; 15:1163-1169. https://doi.org/10.1038/nm.2009.

47. Sheldrake HM, Patterson LH. Function and antagonism of beta3 integrins in the development of cancer therapy. Curr Cancer Drug Targets. 2009; 9:519-540.

48. Skuli N, Monferran S, Delmas C, Favre G, Bonnet J, Toulas C. Cohen-Jonathan Moyal E. Alphavbeta3/alphavbeta5 integrins-FAK-RhoB: a novel pathway for hypoxia regulation in glioblastoma. Cancer Res. 2009; 69:33083316. https://doi.org/10.1158/0008-5472.CAN-08-2158.

49. Garetto S, Sardi C, Martini E, Roselli G, Morone D, Angioni R, Cianciotti BC, Trovato AE, Franchina DG, Castino GF, Vignali D, Erreni M, Marchesi F, et al. Tailored chemokine 
receptor modification improves homing of adoptive therapy $\mathrm{T}$ cells in a spontaneous tumor model. Oncotarget. 2016; 7:43010-43026. https://doi.org/10.18632/oncotarget.9280.

50. Mulgrew K, Kinneer K, Yao XT, Ward BK, Damschroder MM, Walsh B, Mao SY, Gao C, Kiener PA, Coats S, Kinch MS, Tice DA. Direct targeting of alphavbeta3 integrin on tumor cells with a monoclonal antibody, Abegrin. Mol Cancer Ther. 2006; 5:3122-3129. https://doi. org/10.1158/1535-7163.MCT-06-0356.

51. Nabors LB, Mikkelsen T, Rosenfeld SS, Hochberg F, Akella NS, Fisher JD, Cloud GA, Zhang Y, Carson K, Wittemer SM, Colevas AD, Grossman SA. Phase I and correlative biology study of cilengitide in patients with recurrent malignant glioma. J Clin Oncol. 2007; 25:1651-1657. https://doi.org/10.1200/JCO.2006.06.6514.

52. Liu Z, Wang F, Chen X. Integrin alpha(v)beta(3)-Targeted Cancer Therapy. Drug Dev Res. 2008; 69:329-339. https:// doi.org/10.1002/ddr.20265.

53. Landen CN, Kim TJ, Lin YG, Merritt WM, Kamat AA, Han LY, Spannuth WA, Nick AM, Jennnings NB, Kinch MS, Tice D, Sood AK. Tumor-selective response to antibodymediated targeting of alphavbeta3 integrin in ovarian cancer. Neoplasia. 2008; 10:1259-1267.

54. Beer AJ, Schwaiger M. Imaging of integrin alphavbeta3 expression. Cancer Metastasis Rev. 2008; 27:631-644. https://doi.org/10.1007/s10555-008-9158-3.

55. Dijkgraaf I, Terry SY, McBride WJ, Goldenberg DM, Laverman P, Franssen GM, Oyen WJ, Boerman OC. Imaging integrin alpha-v-beta-3 expression in tumors with an 18 F-labeled dimeric RGD peptide. Contrast Media Mol Imaging. 2013; 8:238-245. https://doi.org/10.1002/ cmmi.1523.
56. Debergh I, Van Damme N, De Naeyer D, Smeets P, Demetter P, Robert P, Carme S, Pattyn P, Ceelen W. Molecular imaging of tumor-associated angiogenesis using a novel magnetic resonance imaging contrast agent targeting $\alpha v \beta 3$ integrin. Ann Surg Oncol. 2014; 21:20972104. https://doi.org/10.1245/s10434-013-3444-1.

57. Edwards WB, Akers WJ, Ye Y, Cheney PP, Bloch S, Xu B, Laforest R. Achilefu, S. Multimodal imaging of integrin receptor-positive tumors by bioluminescence, fluorescence, gamma scintigraphy, and single-photon emission computed tomography using a cyclic RGD peptide labeled with a near-infrared fluorescent dye and a radionuclide. Mol Imaging. 2009; 8:101-110.

58. Withofs N, Signolle N, Somja J, Lovinfosse P, Nzaramba EM, Mievis F, Giacomelli F, Waltregny D, Cataldo D, Gambhir SS. Hustinx R. 18F-FPRGD2 PET/CT imaging of integrin $\alpha v \beta 3$ in renal carcinomas: correlation with histopathology. J Nucl Med. 2015; 56:361-364. https://doi. org/10.2967/jnumed.114.149021.

59. Haubner R, Weber WA, Beer AJ, Vabuliene E, Reim D, Sarbia M, Becker KF, Goebel M, Hein R, Wester HJ, Kessler H. Schwaiger M. Noninvasive visualization of the activated alphavbeta3 integrin in cancer patients by positron emission tomography and [18F]Galacto-RGD. PLoS Med. 2005; 2:e70. https://doi.org/10.1371/journal.pmed.0020070.

60. Reinmuth N, Liu W, Ahmad SA, Fan F, Stoeltzing O, Parikh AA, Bucana CD, Gallick GE, Nickols MA, Westlin WF, Ellis LM. Alphavbeta3 integrin antagonist S247 decreases colon cancer metastasis and angiogenesis and improves survival in mice. Cancer Res. 2003; 63:2079-2087. 